\title{
An Improved Particle Swarm Optimization with Chaotic Inertia Weight and Acceleration Coefficients for Optimal Extraction of PV Models Parameters
}

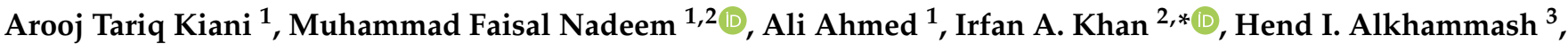 \\ Intisar Ali Sajjad ${ }^{1}$ (D) and Babar Hussain ${ }^{4}$ \\ 1 Department of Electrical Engineering, University of Engineering and Technology Taxila, \\ Taxila 47080, Pakistan; aroojkiyani@outlook.com (A.T.K.); faisal.nadeem@uettaxila.edu.pk (M.F.N.); \\ engr.ranaali332@gmail.com (A.A.); intisar.ali@uettaxila.edu.pk (I.A.S.) \\ 2 Clean and Resilient Energy Systems (CARES) Research Laboratory, Texas A\&M University, \\ Galveston, TX 77553, USA \\ 3 Department of Electrical Engineering, College of Engineering, Taif University, P.O. Box 11099, \\ Taif 21944, Saudi Arabia; Khamash.h@tu.edu.sa \\ 4 Department of Electrical Engineering, Pakistan Institute of Engineering and Applied Sciences (PIEAS), \\ Islamabad 44000, Pakistan; b.hussain@pieas.edu.pk \\ * Correspondence: irfankhan@tamu.edu
}

check for updates

Citation: Kiani, A.T.; Nadeem, M.F.; Ahmed, A.; Khan, I.A.;

Alkhammash, H.I.; Sajjad, I.A.; Hussain, B. An Improved Particle Swarm Optimization with Chaotic Inertia Weight and Acceleration Coefficients for Optimal Extraction of PV Models Parameters. Energies 2021, 14, 2980. https://doi.org/10.3390/ Ten14112980

\section{Academic Editors:}

Alessandro Cannavale,

Filippo Spertino and Paolo Di Leo

Received: 1 April 2021

Accepted: 13 May 2021

Published: 21 May 2021

Publisher's Note: MDPI stays neutral with regard to jurisdictional claims in published maps and institutional affiliations.

Copyright: (c) 2021 by the authors. Licensee MDPI, Basel, Switzerland. This article is an open access article distributed under the terms and conditions of the Creative Commons Attribution (CC BY) license (https:/ / creativecommons.org/licenses/by/ $4.0 /)$.

\begin{abstract}
The efficiency of PV systems can be improved by accurate estimation of PV parameters. Parameter estimation of PV cells and modules is a challenging task as it requires accurate operation of PV cells and modules followed by an optimization tool that estimates their associated parameters. Mostly, population-based optimization tools are utilized for PV parameter estimation problems due to their computational intelligent behavior. However, most of them suffer from premature convergence problems, high computational burden, and often fall into local optimum solution. To mitigate these limitations, this paper presents an improved variant of particle swarm optimization (PSO) aiming to reduce shortcomings offered by conventional PSO for estimation of PV parameters. PSO is improved by introducing two strategies to control inertia weight and acceleration coefficients. At first, a sine chaotic inertia weight strategy is employed to attain an appropriate balance between local and global search. Afterward, a tangent chaotic strategy is utilized to guide acceleration coefficients in search of an optimal solution. The proposed algorithm is utilized to estimate the parameters of the PWP201 PV module, RTC France solar cell, and a JKM330P-72 PV module-based practical system. The obtained results indicate that the proposed technique avoids premature convergence and local optima stagnation of conventional PSO. Moreover, a comparison of obtained results with techniques available in the literature proves that the proposed methodology is an efficient, effective, and optimal tool to estimate PV modules and cells' parameters.
\end{abstract}

Keywords: acceleration coefficients; chaotic and tangent; inertia weight; parameter estimation; solar cell and modules

\section{Introduction}

Electric energy plays a vital role in the existence of various sectors such as industries, agriculture, manufacturing, and housing. Fossil fuels have been used significantly for many years to produce electric energy, but increasing fuel prices and reduction in their availability focused the attention of researchers towards sustainable sources of energy $[1,2]$. Fossil fuels such as oil, coal, and gas are also responsible for carbon emission resulting in global environmental hazards [3]. Subsequently, renewable energy sources such as solar, tidal, wind, and biomass provide clean, safe, and abundant energy for utilization. The second most abundant renewable energy source after the wind is solar energy [4], which is utilized in many areas of life such as irrigation [5], solar farming [6], electric vehicles [7], 
and street lighting [8]. A photovoltaic (PV) system is required to convert solar energy into a useful source of energy (electricity) [9]. There are different configurations through which PV systems can operate, such as grid-connected, standalone, and hybrid systems [10]. In the grid-connected configuration, the PV system has a connection with an electric grid for generated energy utilization. The standalone configured PV system is independent of the electric grid and requires separate battery storage. In contrast, the hybrid system is connected with an electric grid and has a battery storage system also.

The variation in energy production from PV systems is based on the difference in size, location, technology, and design [11]. Largely, different types of solar cells are utilized based on a different form of silicon, such as ploy-crystalline, monocrystalline, and amorphous thin film [12]. Each type of silicon solar cell offers different efficiency and cost. The highest efficiency amongst all is provided by a monocrystalline solar cell, which is about $17-25 \%$ but is the most expensive because of the surplus silicon material obtained while cutting it to achieve the required shape. Polycrystalline provides an efficiency of about $12-18 \%$ and is less efficient in comparison to the monocrystalline solar cell as it involves recombination of numerous grain boundaries but is less expensive due to its easier production. Amorphous thin-film cells offer the most cost-effective production but are the least efficient. Accurate modeling of the PV model based on current-voltage information is a crucial challenge to improve the PV system's overall efficiency $[13,14]$. Though the current-voltage pair curve is validated under the standard test condition (STC), the subsequent PV model's efficiency is highly affected by external environmental conditions such as temperature and irradiance. To model these nonlinearities, various models have been developed, such as the single diode model (SDM), double diode model (DDM), multi diode, and multidimensional diode model [15]. The accuracy and complexity of their equivalent electric circuits depend upon the type of model used. SDM and DDM have mostly utilized models to estimate associated PV parameters [16]. SDM is simple but provides the least accuracy. Contrary to this, DDM offers improved accuracy at the cost of greater computational burden [17]. Estimation of unknown parameters associated with the utilized model is crucial to improve the efficiency of the PV system.

To estimate these PV parameters, various techniques have been utilized by researchers, which can be categorized as; analytical, deterministic, and computationally intelligent (CI) techniques. Analytical techniques [18-20] require a set of mathematical equations comprised of certain known and unknown parameters to be identified. Although, these approaches offer less computational burden and simplicity but provide an inaccurate set of I-V data while estimating PV parameters. Deterministic approaches involve accurate initial guesses, and any error leads to an inaccurate solution. Newton Raphson method [21] and Lambert W-function [22-24] have been utilized to estimate PV parameters.

However, $\mathrm{PV}$ parameter estimation is a complex, multimodal, and non-linear problem due to which deterministic approaches may face local minima stagnation, resulting in a less efficient solution if the initial guess is inaccurate. CI techniques are considered as an efficient alternative tool to solve the PV parameter estimation problem, and various CI techniques have been developed in the literature. In [25], solar PV characteristics have been precisely predicted using bacterial foraging algorithm (BFA) with modified equations to derive voltage at maximum power point and open-circuit conditions. However, the authors have compared the obtained results with only two other techniques, which are genetic algorithm (GA) and artificial immune system (AIS). Optimal PV parameters were extracted for double and single diode models using the flower pollination algorithm (FPA) in [26] but the randomness involved in switching probability of FPA leads to local minima stagnation of algorithm. Cuckoo search algorithm (CSA) is proposed in [27] for optimal estimation of PV parameters using single and double diode models. However, the referred studies suffer from slow convergence characteristics and local optima stagnation due to complexity in the PV parameter estimation problem. In [28], differential evolution (DE) has been proposed to measure PV parameters for different types of PV modules (thin-film, polycrystalline, and monocrystalline) at varying environmental conditions. However, the 
parameters involved in DE tend to exceed boundary constraints due to the differential nature resulting in low quality solution.

In [29], authors have proposed a penalty function in DE to restrict parameter values in feasible regions after crossover operation but the referred study compared the proposed technique with few other techniques, which makes it less effective. Additionally, the authors validated the performance of the proposed technique on PV modules only and not considered the solar cell. In [30], a disruptor operator has been modeled to avoid local minima stagnation in the moth search algorithm (MSA) to estimate PV parameters. The authors have validated the proposed technique on just a single case study (triple junction PV panel).

Several other CI techniques have been proposed for parameter estimation of PV modules and cells such as the improved sine cosine algorithm (ISCA) [31], coyote optimization algorithm (COA) [17], improved cuckoo search optimization (ICSO) [32], enhanced adaptive differential evolution algorithm (EADE) [33], Levy flight based backtracking search algorithm (LFBSA) [34], basic flower pollination algorithm (BFPA) [35], bacterial foraging optimization approach (BFOA) [36], enhanced teaching learning-based algorithm (ETLBO) [37], improved teaching learning-based optimization (GOTLBO) [38], comparative learning-based PSO (CLPSO) [39], guaranteed convergence PSO (GCPSO) [13], cuckoo search (CS) [40], ABC [41], teaching learning-based optimization (TLBO) [42], and teaching learning-based ABC optimizer (TLABC) [43].

Despite, numerous advantages posed by $\mathrm{CI}$ techniques, they offer some limitations such as local minima stagnation and slow and premature convergence leading to inaccurate solutions [44]. Additionally, many of these techniques involve a large number of mathematical equations posing a higher computational burden. On the other hand, particle swarm optimization (PSO) is a widely adopted optimization algorithm due to its simplicity and ease in implementation, but the premature convergence and local optima stagnation make it unfavorable for complex problems like PV parameter estimation. Therefore, various researchers have integrated other techniques with PSO to mitigate these limitations. In [45], wind driven optimization-based hybrid algorithm (WDOWOAPSO) integrated two algorithms (wind driven and whale optimization) with PSO for the PV parameter estimation. In [46], PSO has been hybridized with simulated annealing (SA) resulting in HPSOSA. In [47] Nelder Mead and PSO have been hybridized to obtain NM-MPSO. In [48] whale optimization algorithm has been integrated with PSO resulting in WOAPSO for parameter estimation of PV cells and modules. Though the hybrid techniques effectively mitigate local minima stagnation because of their capability of effective global search. However, tuning of various parameters are involved, which requires trial and error, resulting in the least efficacy. Additionally, a higher computational burden is involved as the number of algorithms increases.

To conquer all the above-mentioned limitations, researchers presented improved/modified variants of $\mathrm{PSO}$, which pose a lesser computational burden, require a minimum number of tuning parameters, and provide optimal results while solving premature convergence and local minima stagnation problems. In [49], time-varying acceleration coefficient PSO (TVACPSO) has been presented in which personal and social acceleration coefficients decrease and increase respectively with iterations. The proposed technique was validated on the RTC France solar cell and PWP201 module. However, the authors have not modified inertia weight to provide an optimum balance between local and global search. Moreover, the referred technique should be implemented on a practical system to test its effectiveness when exposes to real environmental conditions. In [50], another variant of PSO, chaotic inertia weight PSO (CIWPSO) has been proposed for PV parameter estimation utilizing chaotic search theory to control inertia weight parameter. Similarly, simulated annealing inertia weight PSO (SAIW-PSO) [51] utilized a simulated annealing strategy for controlling inertia weight. However, both referred studies have not updated acceleration coefficients and utilized only the RTC France solar cell for validation making the study less effective. The proposed technique should be implemented on a cell, module, and a practical PV system to prove its effectiveness. In [52] an exponential 
function-based inertia weight PSO (DEDIWPSO) has been proposed in which a dynamic exponential function-based inertia weight strategy is utilized to balance local and global search. This technique is validated on a solar cell, module, and a practical PV system however, the referred technique also offers some limitations. The referred technique only tunes the inertia weight, not acceleration coefficients of PSO, whereas randomness in acceleration coefficients may lead to premature convergence, hence providing a low-quality solution.

From the detailed study of literature, it is evident that the area of PV parameter estimation gained a huge interest. Researchers are in search of new techniques, which can provide an optimal solution with the least computational burden and complexity. In this paper, authors presented a modified version of PSO, which has the ability to tune both inertia weight and acceleration coefficients effectively to provide an optimal solution. Authors also validate the presented technique on a cell, module, and practical system to prove its efficiency and accuracy. Additionally, the authors have compared the obtained results with various techniques from the literature. The main contributions of the paper are;

- A computationally intelligent algorithm is presented, which utilizes two-step modification inspired by chaos theory and trigonometric functions to improve search capability of PSO named as particle swarm optimization algorithm with sine chaotic inertia weight and tangent chaotic acceleration coefficients (PSO-ST).

- Newton Raphson method (NRM) is employed for accurate estimation of current values, which are utilized to compute objective function formulation.

- The proposed technique is validated using three different case studies, including the PWP201 PV module, RTC France solar cell, and JKM330P-72 PV module-based practical system.

- A comparison of the obtained results with various techniques from literature is also provided, which shows that the proposed technique can effectively, efficiently, and optimally estimate the PV parameters for different case studies.

The remaining paper is arranged as: Section 2 presents mathematical modeling of PV models, Section 3 formulates objective function for the estimation of PV parameters, Section 4 presents an efficient approach aiming to solve PV parameter estimation problem, Section 5 provides obtained results and validates them by comparing with other techniques, and Section 6 finally concludes the paper.

\section{PV Modeling}

PV cells and modules' electrical characteristics are modeled by their equivalent circuits based on the Shockley's diode equation [45]. To represent non-linear characteristics of PV models, the effect of losses is considered along with an ideal diode model (IDM). An IDM comprises a photon current source in parallel with a diode, possessing zero losses. Series and parallel resistances in SDM and DDM of cell and module represent $\mathrm{p}-\mathrm{n}$ junction losses and leakage current losses. This paper utilized SDM and DDM for the estimation of associated PV parameters for three different case studies.

\subsection{Single-Diode Model}

Figure 1 represents an electrical equivalent circuit of SDM comprises of a photon current source, a semiconductor device (diode) in combination with series and parallel resistances. Solar irradiance causes photon current $I_{\text {photon }}$ to flow in a PV cell, which leads to the recombination and diffusion of electrons in the $p-n$ junction represented by the diode ideality factor $a$. Series resistance $R_{s e}$ represents the losses associated with electrode material, diode resistance, and contact resistance. Furthermore, leakage current loss in the process of diffusion and recombination of electrons in $\mathrm{p}-\mathrm{n}$ junction is modeled by parallel resistance $R_{P}$. Application of Kirchhoff's current law (KCL) on Figure 1 gives us (1) [13].

$$
I=I_{\text {photon }}-I_{\text {diode }}-\left(\frac{\mathrm{V}+\mathrm{I} \times R_{s e}}{R_{P}}\right)
$$




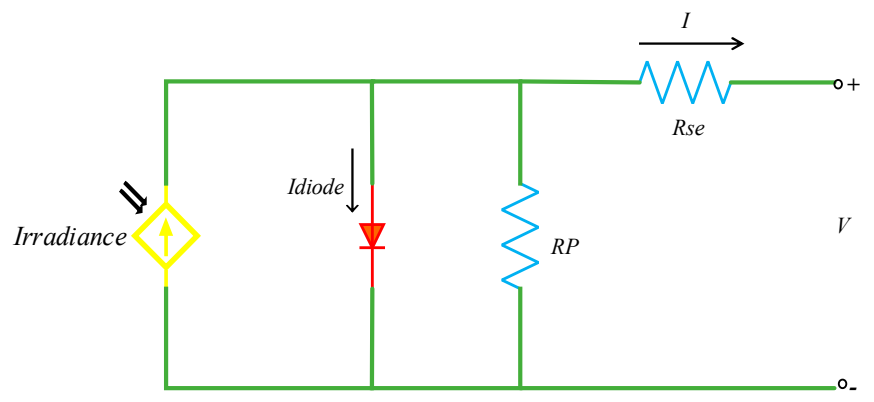

Figure 1. Electrical equivalent model of SDM.

Here, I represents output current obtained from respective PV model. $I_{\text {diode }}$ is the diode current as explained by the Shockley equation in (2).

$$
I_{\text {diode }}=I_{0}\left[\exp \left(\frac{V_{\text {diode }}}{V_{t} \times a}\right)-1\right]
$$

$I_{0}$ represents the saturation current of diode and $V_{\text {diode }}$ illustrates diode voltage as; $V_{\text {diode }}=\mathrm{V}+\mathrm{I} \times R_{\text {se }}$.

$$
\begin{gathered}
I_{\text {diode }}=I_{0}\left[\exp \left(\frac{\mathrm{V}+\mathrm{I} \times R_{s e}}{a \times V_{t}}\right)-1\right] \\
V_{t}=\frac{N o_{S e} \times \mathrm{Te} \times k}{e}
\end{gathered}
$$

$V_{t}$ represents thermal voltage, Te is the temperature in Kelvin, $k$ is Boltzmann constant, $e$ is electron charge, and $\mathrm{No}_{S e}$ represents the number of cells connected in series. By substituting (3) in (1) we have,

$$
I=I_{\text {photon }}-I_{0}\left[\exp \left(\frac{V+I \times R_{s e}}{a \times V_{t}}\right)-1\right]-\left(\frac{V+I \times R_{s e}}{R_{P}}\right)
$$

Equation (5) represents the mathematical model of SDM for cell and module. Set of five unknown lumped parameters associated with SDM need to be estimated are $\left(I_{\text {photon }}, I_{0}, R_{s e}, R_{P}, a\right)$.

\subsection{Double-Diode Model}

Figure 2 represents an electrical equivalent circuit of DDM comprises of a photon current source, two semiconductor devices (diode1 and diode2) in combination with series and parallel resistances. The diffusion process and charge recombination in the $\mathrm{p}-\mathrm{n}$ junction are represented by the ideality factors of both diodes $a_{1}$ and $a_{2}$, respectively. Diffusion current and current due to recombination of charges are represented by $I_{\text {diode1 } 1}$ and $I_{\text {diode } 2}$ respectively. Application of KCL on Figure 2 gives,

$$
I=I_{\text {photon }}-I_{\text {diode } 1}-I_{\text {diode } 2}-\left(\frac{V+I \times R_{s e}}{R_{P}}\right)
$$

Shockley diode equation provides (7) and (8),

$$
\begin{aligned}
& I_{\text {diode } 1}=I_{01}\left[\exp \left(\frac{V_{\text {diode }}}{a_{1} \times V_{t}}\right)-1\right] \\
& I_{\text {diode2 }}=I_{02}\left[\exp \left(\frac{V_{\text {diode }}}{a_{2} \times V_{t}}\right)-1\right]
\end{aligned}
$$




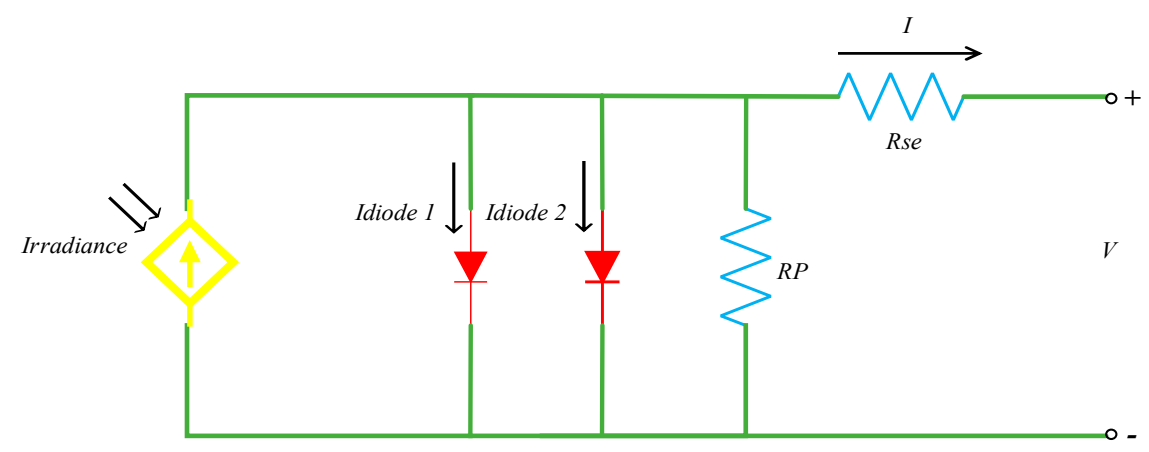

Figure 2. Electrical equivalent model of DDM.

Substituting (7) and (8) in (6) provides (9),

$I=I_{\text {photon }}-I_{01}\left[\exp \left(\frac{V+I \times R_{s e}}{a_{1} \times V_{t}}\right)-1\right]-I_{02}\left[\exp \left(\frac{V+I \times R_{s e}}{a_{2} \times V_{t}}\right)-1\right]-\left(\frac{V+I \times R_{s e}}{R_{P}}\right)$

Equation (9) represents the mathematical model of DDM for the cell and module. Set of seven unknown lumped parameters associated with DDM that need to be estimated are $\left(I_{\text {photon }}, I_{01}, I_{02}, R_{s e}, R_{P}, a_{1}, a_{2}\right)$.

\section{Formulation of Objective Function}

Mathematical modeling of respective PV models is obtained aiming to estimate associated parameters accurately for a given set of I-V curve data. In this study, parameter estimation is considered as an optimization problem solved using an efficient optimization methodology to obtain the set of PV parameters that provide the best approximation to the given data. It can be achieved by minimizing the difference between experimental and computed values of current obtained from the presented approach. This difference is obtained in the literature utilizing a fitness indicator root mean square error (RMSE), and in this paper, it is selected as an objective function (OF) for the PV parameter estimation problem and is given as below [52],

$$
O F=\operatorname{Min}(R M S E)=\operatorname{Min}\left(\sqrt{\frac{\sum_{z=1}^{n}\left(I_{z}-I_{\left(V_{z}, t\right)}\right)^{2}}{N}}\right)
$$

$N$ is the total number of given pairs of the I-V curve. $I_{z}$ and $I_{\left(V_{z}, t\right)}$ represent experimental and computed current, respectively. As information about parameters is not provided and models are well specified. Hence any minimization in RMSE is considered significant.

\subsection{Single-Diode Model}

For SDM, five unknown parameters $\left(I_{\text {photon }}, I_{0}, R_{s e}, R_{P}, a\right)$ were obtained by calculating the values of current that provide the minimum value of RMSE. This computed current $I_{\left(V_{Z}, t\right)}$ was obtained by using the Newton Raphson method (NRM) as shown in Figure 3. At first, $f\left(I_{\left(V_{Z}, t\right)}\right)=0$ was solved as represented in (11). Then, NRM evaluates $f\left(I_{\left(V_{Z}, t\right)}\right)$ effectively for a specified tolerance level $\left(f\left(I_{\left(V_{Z}, t\right)}\right)>10^{-10}\right)$ utilizing the derivative of $f\left(I_{\left(V_{Z}, t\right)}\right)$ obtained from (12) for SDM.

$f\left(I_{\left(V_{Z}, t\right)}\right)=\left(I_{\text {photon }}-I_{0}\left[\exp \left(\frac{V_{I}+I_{\left(V_{Z}, t\right)} \times R_{s e}}{a \times V_{t}}\right)-1\right]-\left(\frac{V_{I}+I_{\left(V_{Z}, t\right)} \times R_{s e}}{R_{P}}\right)\right)-I_{\left(V_{Z}, t\right)}$ 


$$
\frac{\partial f\left(I_{\left(V_{Z}, t\right)}\right)}{\partial I_{\left(V_{Z}, t\right)}}=-\left(\frac{I_{0} \times R_{s e}\left[\exp \left(\frac{V_{I}+I_{\left(V_{Z}, t\right.} \times R_{s e}}{a \times V_{t}}\right)\right]}{a \times V_{t}}\right)-\frac{R_{s e}}{R_{P}}-1
$$

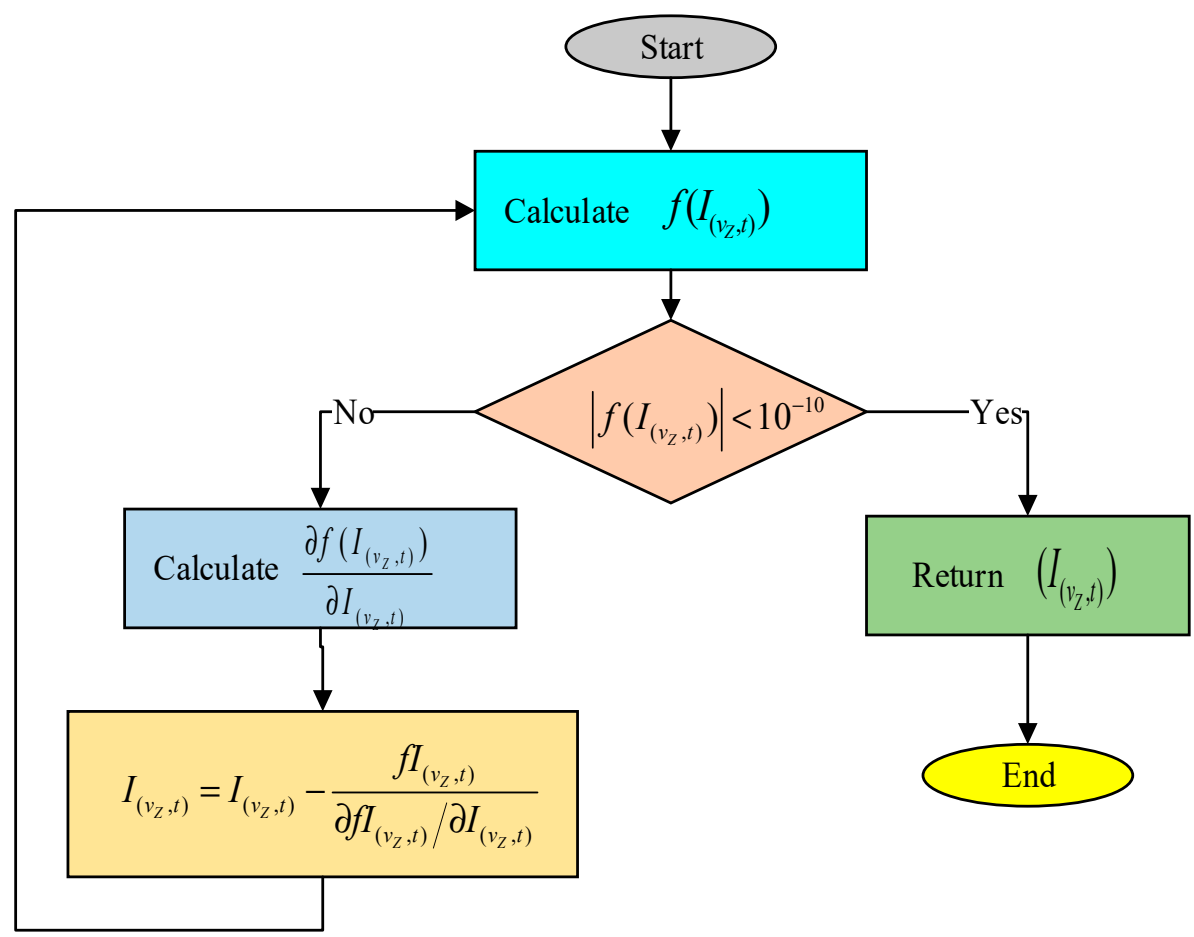

Figure 3. Newton Raphson method for the formulation of the objective function.

For SDM, five unknown parameters were bounded within the limits as given in Table 1 for three different case studies. Case 1, RTC France solar cell; Case 2, Photowatt-PWP201 PV module and JKM330P-72 PV module based practical system.

Table 1. Bounds of SDM for three different case studies.

\begin{tabular}{ccccccc}
\hline & \multicolumn{2}{c}{ Case-1 } & \multicolumn{2}{c}{ Case-2 } & \multicolumn{2}{c}{ Case-3 } \\
\cline { 2 - 7 } Five Parameters & $\begin{array}{c}\text { Upper } \\
\text { Bounds }\end{array}$ & $\begin{array}{c}\text { Lower } \\
\text { Bounds }\end{array}$ & $\begin{array}{c}\text { Upper } \\
\text { Bounds }\end{array}$ & $\begin{array}{c}\text { Lower } \\
\text { Bounds }\end{array}$ & $\begin{array}{c}\text { Upper } \\
\text { Bounds }\end{array}$ & $\begin{array}{c}\text { Lower } \\
\text { Bounds }\end{array}$ \\
\hline$I_{\text {photon }}(\mathrm{A})$ & 1 & 0 & 1.2 & 0 & 10 & 0 \\
$I_{0}(\mathrm{~A})$ & $1 \times 10^{-5}$ & $1 \times 10^{-12}$ & $1 \times 10^{-5}$ & $1 \times 10^{-12}$ & $1 \times 10^{-5}$ & $1 \times 10^{-12}$ \\
$a$ & 2.5 & 0.5 & 2.5 & 0.5 & 2.5 & 0.5 \\
$R_{s e}(\Omega)$ & 0.5 & 0.001 & 2 & 0.001 & 2 & 0.001 \\
$R_{P}(\Omega)$ & 100 & 0.001 & 5000 & 0.001 & 5000 & 0.001 \\
\hline
\end{tabular}

\subsection{Double-Diode Model}

For DDM, seven unknown parameters $\left(I_{\text {photon }}, I_{01}, I_{02}, R_{s e}, R_{P}, a_{1}, a_{2}\right)$ were obtained by calculating the values of current that provide the minimum value of RMSE. This computed current $I_{\left(V_{Z}, t\right)}$ was obtained by using the Newton Raphson method (NRM) as shown in Figure 3 by replacing (11) and (12) for SDM with (13) and (14) for DDM.

$$
f\left(I_{\left(V_{Z}, t\right)}\right)=\left(I_{\text {photon }}-I_{01}\left[\exp \left(\frac{V_{I}+I_{\left(V_{Z}, t\right)} \times R_{s e}}{a_{1} \times V_{t}}\right)-1\right]-I_{02}\left[\exp \left(\frac{V_{I}+I_{\left(V_{Z}, t\right)} \times R_{s e}}{a_{2} \times V_{t}}\right)-1\right]-\left(\frac{V_{I}+I_{\left(V_{Z}, t\right)} \times R_{s e}}{R_{P}}\right)\right)-I_{\left(V_{Z}, t\right)}
$$




$$
\frac{\partial f\left(I_{\left(V_{Z}, t\right)}\right)}{\partial\left(I_{\left(V_{Z}, t\right)}\right)}=-\left(\frac{R_{s e} \times I_{01}\left[\exp \left(\frac{V_{I}+I_{\left(V_{Z}, t\right)} \times R_{s e}}{a_{1} \times V_{t}}\right)\right]}{a_{1} \times V_{t}}\right)-\left(\frac{R_{s e} \times I_{02}\left[\exp \left(\frac{V_{I}+I_{\left(V_{Z}, t\right)} \times R_{s e}}{a_{2} \times V_{t}}\right)\right]}{a_{2} \times V_{t}}\right)-\frac{R_{s e}}{R_{P}}-1
$$

For DDM, seven unknown parameters are bounded within the limits as given in Table 2 for three different case studies. Case 1, RTC France solar cell; Case 2, PhotowattPWP201 PV module; Case 3, JKM330P-72 PV module based practical system.

Table 2. Bounds of DDM for three different case studies.

\begin{tabular}{lllllll}
\hline \multirow{2}{*}{ Seven Parameters } & \multicolumn{2}{c}{ Case-1 } & \multicolumn{2}{c}{ Case-2 } & \multicolumn{2}{c}{ Case-3 } \\
\cline { 2 - 7 } & $\begin{array}{c}\text { Upper } \\
\text { Bounds }\end{array}$ & $\begin{array}{c}\text { Lower } \\
\text { Bounds }\end{array}$ & $\begin{array}{c}\text { Upper } \\
\text { Bounds }\end{array}$ & $\begin{array}{c}\text { Lower } \\
\text { Bounds }\end{array}$ & $\begin{array}{c}\text { Upper } \\
\text { Bounds }\end{array}$ & $\begin{array}{c}\text { Lower } \\
\text { Bounds }\end{array}$ \\
\hline$I_{\text {photon }}(\mathrm{A})$ & 1 & 0 & 1.2 & 0 & 10 & 0 \\
$I_{01}(A)$ & $1 \times 10^{-5}$ & $1 \times 10^{-12}$ & $1 \times 10^{-5}$ & $1 \times 10^{-12}$ & $1 \times 10^{-5}$ & $1 \times 10^{-12}$ \\
$I_{02}(A)$ & $1 \times 10^{-5}$ & $1 \times 10^{-12}$ & $1 \times 10^{-5}$ & $1 \times 10^{-12}$ & $1 \times 10^{-5}$ & $1 \times 10^{-12}$ \\
$a_{1}$ & 2.5 & 0.5 & 2.5 & 0.5 & 2.5 & 0.5 \\
$a_{2}$ & 2.5 & 0.5 & 2.5 & 0.5 & 2.5 & 0.5 \\
$R_{s e}(\Omega)$ & 0.5 & 0.001 & 2 & 0.001 & 2 & 0.001 \\
$R_{P}(\Omega)$ & 100 & 0.001 & 5000 & 0.001 & 5000 & 0.001 \\
\hline
\end{tabular}

\section{Proposed Improved Particle Swarm Optimization}

Particle swarm optimization (PSO) is a swarm-based optimization algorithm proposed in [53], stimulated by the principle of cooperation in a society, inspired by the foraging of birds and fishes. The population comprises of an $x$ number of particles where every particle characterizes a solution in a search space. Each particle holds some position and velocity, which are updated iteratively using their respective mathematical equations. Velocity of $x^{\text {th }}$ particle is updated using information about the personal and global best experiences of particle. Utilizing personal experience known as personal best $\mathcal{P}_{\text {best }}$ and global experience known as global best $\mathcal{G}_{\text {best }}$, particles explore an optimal solution in a multidimensional search space. The performance of each particle is evaluated utilizing a predefined $\mathrm{OF}$ in every iteration. The movement of every particle in search space is represented by (15) and (16).

$$
\begin{gathered}
\kappa_{x}(i t+1)=w \times \kappa_{x}(i t)+C_{1} \times r_{1}\left(\mathcal{P}_{\text {best }_{m}}-\mathcal{S}_{x}\right)+C_{2} \times r_{2}\left(\mathcal{G}_{\text {best }_{m}}-\mathcal{S}_{x}\right) \\
\mathcal{S}_{x}(i t+1)=\mathcal{S}_{x}(i t)+\kappa_{x}(i t+1)
\end{gathered}
$$

where, $\kappa_{x}$ is velocity and $\mathcal{S}_{x}$ is the position of $x^{\text {th }}$ individual, respectively, $C_{1}$ and $C_{2}$ are coefficients of acceleration. $r_{1}$ and $r_{2}$ are the random numbers between 0 and $1, w$ represents inertia weight coefficient, which provides a balance between exploration and exploitation. PSO has been widely utilized by researchers as it is easy to implement, has fewer controlling variables, offers less computational burden and provides optimal results $[54,55]$. However, while solving multidimensional OF (having several local minima), PSO exhibits a lethargic search mechanism [51], providing a low-quality solution while forcing the algorithm to converge prematurely [13]. Moreover, PSO happens to converge towards local minima due to its elitist behavior. Therefore, this paper presents a twostep improvement in conventional PSO to solve premature convergence and local optima stagnation problem, which improves convergence speed and provides optimal solution for PV parameter estimation. Two-step improvement includes:

1. Sine chaotic inertia weight strategy employed to attain an appropriate balance between local and global search.

2. The tangent chaotic strategy utilized to guide acceleration coefficients towards an optimal solution. 
Both strategies are inspired by the chaos theory and trigonometric functions lead to an improved methodology of conventional PSO that uses sine chaotic inertia weight and tangent chaotic acceleration coefficients (PSO-ST) [56].

\subsection{Sine Chaotic Inertia Weight}

Convergence characteristics of PSO is mainly relying on inertia weight $w$. Therefore, different variants of inertia weight have been proposed in literature to reduce premature convergence problem [57]. Chaos theory deals with the study of chaos, which is a nonlinear dynamic occurrence having randomness, ergodicity, and regularity [58]. Literature studies show that optimization utilizing chaos theory provides optimal results than a stochastic search $[56,59]$. Chaotic inertia weight can explore the search space to a great extent because of its ability to avoid repetition of a state in search space [50]. This paper presents sine chaotic inertia weight strategy, which is a sine iterator based chaotic search function, and its mathematical model is presented as follows,

$$
X_{n+1}=\sin \left(\pi x_{n}\right)
$$

The above equation generates a chaotic sequence $X_{n+1}$ in between 0 and 1 and $w$ is modeled as.

$$
w(i t+1)=\varnothing \times \sin \left(\pi w_{t}\right)+\tau
$$

where, $\varnothing$ and $\tau$ are constants and their values are given in Table 3 . Initial value of $w\left(W_{1}\right)$ is any random number between 0 and 1 . With increasing iterations, $w$ can explore search space approximately in the interval of $[0.2,0.9]$. This sine chaotic inertia weight strategy can improve the global search of conventional PSO while avoiding local optima stagnation.

Table 3. Parametric settings for the proposed algorithm provided by [56].

\begin{tabular}{cc}
\hline Parameters & Settings \\
\hline$\varnothing$ & 0.9 \\
$\tau$ & 0 \\
$\mathrm{M}$ & 4 \\
$\Delta$ & 0.2 \\
$\theta$ & 1.5 \\
$p$ & 0.1 \\
$z$ & $(0,1)$ \\
Population & 100 \\
Maxit & 10,000 \\
\hline
\end{tabular}

\subsection{Tangent Chaotic Acceleration Coefficients}

$C_{1}$ and $C_{2}$ are acceleration coefficients of PSO named cognitive and social acceleration coefficients, respectively. With a greater value of $C_{1}$ and smaller value of $C_{2}$, particles tend to move around the search space at early iterations experiencing local search. Contrary to this, at the latter part of the iterative process, particles can travel to explore the search space for a global solution having a smaller value of $C_{1}$ and greater value of $C_{2}$. To obtain these conditions, chaotic mapping is utilized to model $C_{1}$ and $C_{2}$ for an improved search capability of conventional PSO. Logistic mapping for chaos function is given as below;

$$
\mathrm{z}=\mu \times \mathrm{z} \times(1-z)
$$

where $\mu$ is a constant, which controls chaos performance and performed better when $\mu=4$ and $z$ is any number between 0 and 1 . This paper presents tangent acceleration coefficients employed with chaotic terms. Following equations present tangent acceleration coefficients $\left(C_{1}, C_{2}\right)$;

$$
C_{1}=-\delta \times m^{2} \times \tan \left[\frac{\pi}{8} \times\left(1+m^{2}\right)\right]+\theta
$$




$$
\begin{gathered}
C_{2}=-\delta \times(1-m)^{2} \times \tan \left[\frac{\pi}{8} \times\left(1+(1-m)^{2}\right)\right]+\theta \\
m=\frac{i t}{\text { Maxit }}
\end{gathered}
$$

Values for $\delta$ and $\theta$ are specified in Table 3. it is the current iteration whereas, Maxit represents the maximum number of iterations.

A logistic mapping sequence is then generated by taking any value of $z$ between $(0,1)$ to add a chaotic term in (20) and (21), resulting (23) and (24).

$$
\begin{gathered}
C_{1}=-\delta \times m^{2} \times \tan \left[\frac{\pi}{8} \times\left(1+m^{2}\right)\right]+\theta+p \times z \\
C_{2}=-\delta \times(1-m)^{2} \times \tan \left[\frac{\pi}{8} \times\left(1+(1-m)^{2}\right)\right]+\theta+p \times z
\end{gathered}
$$

where $\delta, \theta$, and $p$ are constants and their values are provided in Table 3 . The proposed chaotic acceleration coefficients and sine chaotic inertia weight strategy improve the search capability of conventional PSO and provide faster convergence characteristics. Moreover, due to appropriate selection of tuning parameters of PSO optimum balance between local and global phase is provided, which avoids local minima stagnation and premature convergence problem.

\subsection{Proposed Framework for PV Parameter Estimation}

Following steps are performed for the accurate estimation of parameters associated with the RTC France solar cell, Photowatt-PWP201 PV module, and JKM330P-72 PV module based practical system for both SDM and DDM.

Step 01: Initialize PSO parameters; dimensions (five for SDM and seven for DDM), population size $=100$ and generate initial population between the bounds given in Tables 1 and 2 for SDM and DDM, respectively.

Step 02: After that, following Figure 3, for every particle of population, obtain the calculated current utilizing NRM for each pair of I-V curve data from [52]. Then the performance is evaluated utilizing a specified OF, which is RMSE between the experimental and calculated values of current. The aim is to obtain that set of parameters, which provides the least value of $\mathrm{OF}$.

Step 03: At first iteration, inertia weight is any value between $(0,1)$ whereas acceleration coefficients are calculated using (20) and (21) for obtained particles of population.

Step 04: From there, obtain $\mathcal{P}_{\text {best }}$ (particle's best performance) and $\mathcal{G}_{\text {best }}$ (best performance amongst whole swarm) then calculate the velocity and position of each particle utilizing (15) and (16).

Step 05: Again, evaluate OF following step 02 and update velocity and position utilizing the updated value of $\mathcal{P}_{\text {best }}$ and $\mathcal{G}_{\text {best }}$ as represented in Figure 4. Calculate the inertia weight from (18) using previous information. Repeat step 02 to step 05 until the stopping criteria achieved, which is the maximum number of iterations (Maxit $=10,000)$. 


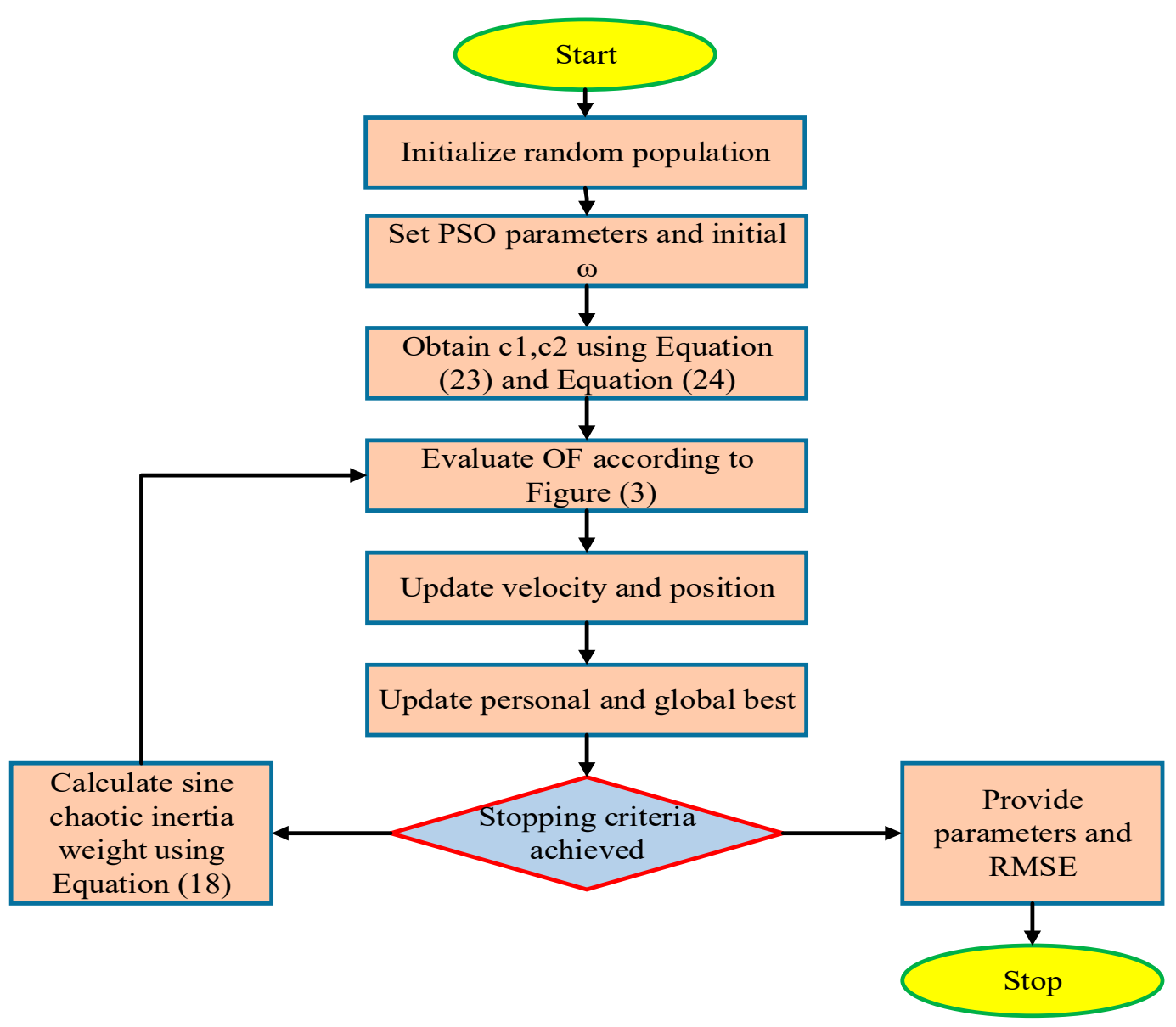

Figure 4. Flowchart of the proposed technique for the parameter estimation of PV models.

Table 3 provides parameter settings of proposed framework utilized in this paper for the parameter estimation of PV models.

\section{Case Studies and Simulation Results}

The performance of the implemented PSO-ST was evaluated in this section for solving the PV parameter estimation problem. Both SDM and DDM are utilized to estimate their associated PV parameters for three different case studies. Case 1, RTC France solar cell; Case 2, Photowatt-PWP201 PV module; Case 3, a practical JKM330P-72 PV module. Experimental data for the first two case studies were obtained from [52], which has been utilized by various researchers to test the performance of their techniques. The third case study includes a practical PV module that provides real experimental data under varying environmental conditions such as irradiance levels and temperature.

\subsection{Case 01: RTC France Solar Cell}

Five and seven unknown parameters for SDM and DDM RTC France solar cells were estimated utilizing the experimental I-V data from [52] obtained at $1000 \mathrm{~W} / \mathrm{m}^{2}$ irradiance level and $33{ }^{\circ} \mathrm{C}$ temperature. The RTC France Solar Cell is $57 \mathrm{~mm}$ in diameter, having characteristic point values of $V_{O C}=0.5727 \mathrm{~V}, I_{S C}=0.7605 \mathrm{~A}, I_{m p p}=0.6755 \mathrm{~V}$, and $V_{m p p}=0.4590 \mathrm{~A}$. The given $\mathrm{I}-\mathrm{V}$ curve contains 26 pairs of $\mathrm{I}-\mathrm{V}$ data. The results from proposed PSO-ST were obtained for 30 independent runs to do a fair comparison.

\subsubsection{Single-Diode Cell}

Five unknown parameters $\left(I_{\text {photon }}, I_{0}, R_{s e}, R_{P}, a\right)$ for the single diode model of the RTC France solar cell obtained from the proposed PSO-ST are presented in Table 4 . The best 
value of RMSE provided by these optimal parameters was $7.730062 \times 10^{-4}$ with standard deviation (SD) of $5.18622 \times 10^{-15}$. Minimum RMSE was tabulated up to six decimal places as its value is highly sensitive. Minimum, mean, and maximum values of RMSE, time, and required number of iterations are also presented in Table 4 . Maximum and minimum values of RMSE were $7.730062 \times 10^{-4}$ and $7.730062 \times 10^{-4}$, respectively followed by required maximum and minimum iterations of 9786 and 691, respectively. Furthermore, 171 and 111 are the maximum and minimum time in seconds respectively, required for PSO-ST to converge. For case study 1, the plot of IAE for SDM is presented in Figure 5 and it can observe from this figure that the implemented technique provides minimum values of IAE for each I-V pair. IAE represents the absolute difference between experimental and computed values of current as given below.

Table 4. Obtained statistical results for the SDM solar cell.

\begin{tabular}{|c|c|c|c|c|c|c|c|}
\hline \multicolumn{2}{|c|}{ Obtained Optimal Parameters } & \multicolumn{2}{|c|}{ OF } & \multicolumn{2}{|c|}{ Iteration } & \multicolumn{2}{|c|}{ Time (s) } \\
\hline$I_{\text {photon }}(\mathrm{A})$ & 0.760766 & Min & $7.730062 \times 10^{-4}$ & Min & 691 & Min & 111 \\
\hline$I_{0}(\mu \mathrm{A})$ & $0.31272 \times 10^{-1}$ & Mean & $7.730062 \times 10^{-4}$ & Mean & 4321 & Mean & 107 \\
\hline$a$ & 1.476241 & Max & $7.730062 \times 10^{-4}$ & Max & 9786 & $\operatorname{Max}$ & 171 \\
\hline$R_{S e}$ & 0.036522 & Std & $5.18622 \times 10^{-15}$ & & & & \\
\hline$R_{P}$ & 53.33940 & & & & & & \\
\hline
\end{tabular}

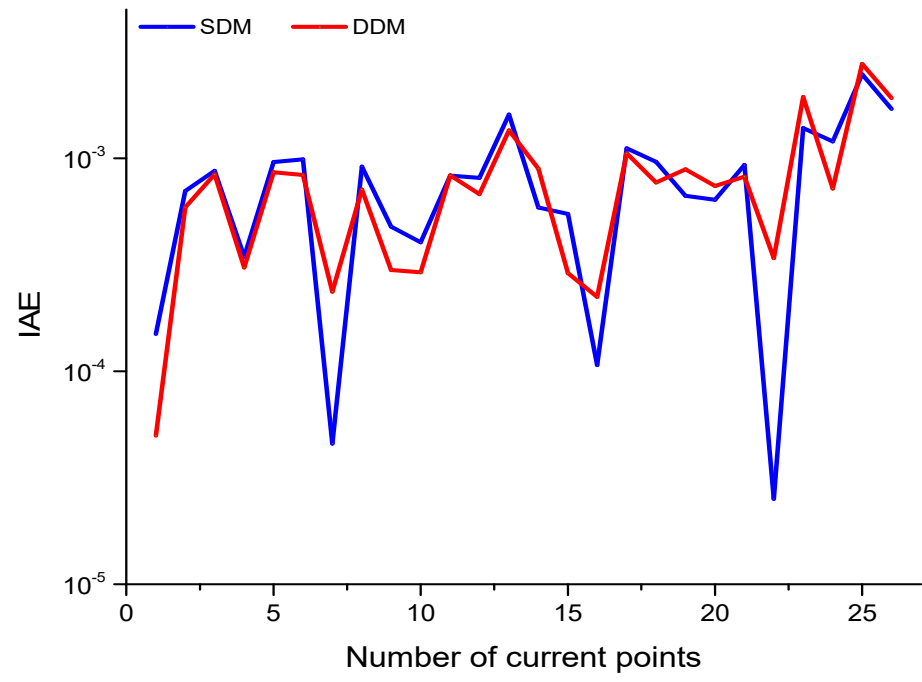

Figure 5. IAE for SDM and DDM, solar cell.

$$
I A E=\left|I_{z}-I_{\left(V_{z}, t\right)}\right|
$$

Experimental and computed values of current are presented in Figure 6, which illustrates that the computed current obtained from an optimal set of parameters effectively approximate given experimental current for $26 \mathrm{I}-\mathrm{V}$ pairs. Moreover, it can be observed that controlling tuning parameters of conventional PSO using the proposed approach provides such optimal PV parameters, which results in almost a similar trend of the I-V curve as obtained by experimental data sets.

A comparison of obtained RMSE and AE from the proposed technique with the techniques available in the literature is also given. Absolute error (AE) is the absolute sum of IAE as given below.

$$
A E=\sum_{z=1}^{N}\left|I_{z}-I_{\left(V_{z}, t\right)}\right|
$$


It can be observed from comparison that the proposed variant of PSO (PSO-ST) outclasses the other available variants of PSO and other state of the art techniques. Moreover, from the comparison of obtained results with conventional PSO it is evident that the PSOST effectively balances the search mechanism of conventional PSO avoiding local minima stagnation and premature convergence problem.

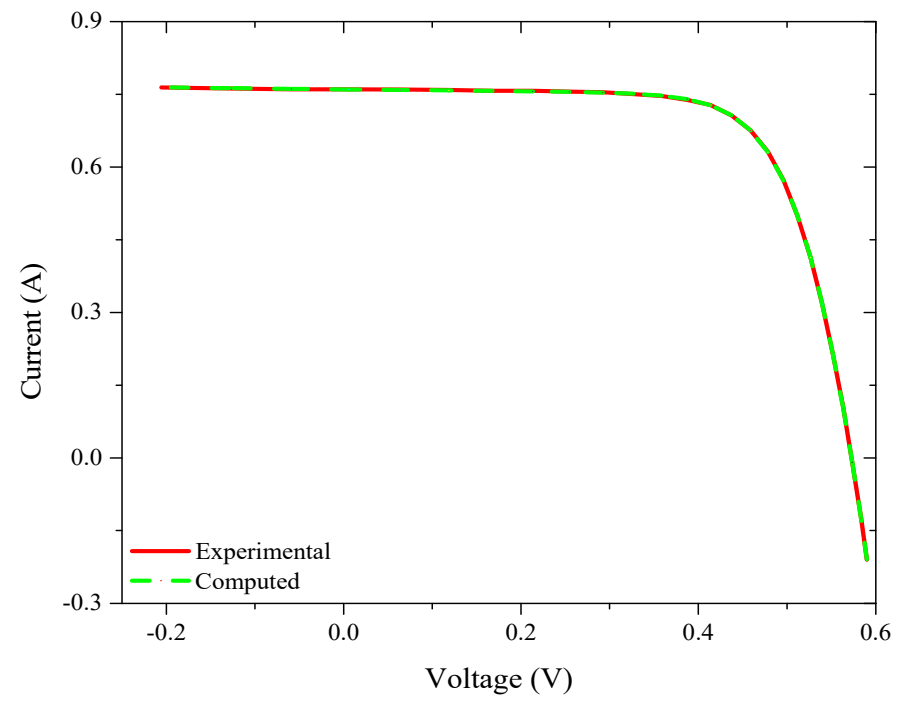

Figure 6. I-V curve for experimental and computed current values of SDM, solar cell.

\subsubsection{Double-Diode Cell}

Similarly, seven unknown parameters $\left(I_{\text {photon }}, I_{01}, I_{02}, R_{s e}, R_{P}, a_{1}, a_{2}\right)$ for double diode model of the RTC France solar cell obtained from the proposed PSO-ST are presented in Table 5. The best RMSE respective to these obtained parameters were $7.183701 \times 10^{-4}$ with STD of $1.318531 \times 10^{-17}$. Minimum, mean, and maximum values of RMSE, time, and required number of iterations are also presented in Table 5. The minimum value of RMSE indicates that proposed PSO-ST effectively explores the search space while avoiding local minima stagnation. Maximum and minimum values of RMSE were $7.218291 \times 10^{-4}$ and $7.183701 \times 10^{-4}$, respectively followed by the required maximum and minimum iterations of 10,000 and 1371, respectively. A greater number of iterations are required to reach the minimum OF value for the double diode model due to its complex behavior. Furthermore, 260 and 138 are the maximum and minimum time required to reach the best value among 30 runs, respectively. Moreover, comparison of PSO-ST with state-of-the-art techniques available in the literature is also provided in Table 6, which demonstrates that the presented technique provides optimal value of RMSE and AE. Furthermore, comparative evaluation of obtained results with conventional PSO strongly supports the presented modifications of inertia weight and acceleration coefficients. For case study 1 , just like SDM a plot of IAE for DDM is also presented, from where it can be clearly seen that the proposed technique provides a minimum error. Experimental and computed values of current are depicted in Figure 7, which illustrates that the computed current obtained from an optimal set of parameters accurately approximates the given experimental current for $26 \mathrm{I}-\mathrm{V}$ pairs. Furthermore, convergence characteristics of the proposed PSO-ST and conventional PSO in Figure 8 for DDM cell indicate that PSO-ST mitigates the premature convergence problem of PSO and provides fast convergence with optimal values of RMSE and PV parameters.

\subsection{Case 02: Photowatt-PWP201 PV Module}

Five and seven unknown parameters for SDM and DDM modules were estimated utilizing the experimental I-V data from [52] obtained at the $1000 \mathrm{~W} / \mathrm{m}^{2}$ irradiance level and $45{ }^{\circ} \mathrm{C}$ temperature. Photowatt-PWP201 is a module having 36 cells in series with characteristic point values of $V_{O C}=16.7785 \mathrm{~V}, I_{S C}=1.0317 \mathrm{~A}, I_{m p p}=0.9120 \mathrm{~A}$, and 
$V_{m p p}=12.6490 \mathrm{~V}$. The given I-V curve contains 26 pairs of IV data. The results from proposed PSO-ST were obtained for 30 independent runs.

Table 5. Obtained statistical results for DDM solar cell.

\begin{tabular}{|c|c|c|c|c|c|c|c|}
\hline \multicolumn{2}{|c|}{ Obtained Optimal Parameters } & \multicolumn{2}{|c|}{ OF } & \multicolumn{2}{|c|}{ Iteration } & \multicolumn{2}{|c|}{ Time (s) } \\
\hline$I_{\text {photon }}(\mathrm{A})$ & 0.76082937 & Min & $7.183701 \times 10^{-4}$ & Min & 1371 & Min & 138 \\
\hline$I_{01}(\mu \mathrm{A})$ & $1.35321 \times 10^{-1}$ & Mean & $7.187382 \times 10^{-4}$ & Mean & 9058 & Mean & 151 \\
\hline$a_{1}$ & 1.40220 & $\operatorname{Max}$ & $7.218291 \times 10^{-4}$ & Max & 10000 & Max & 260 \\
\hline$I_{02,}(\mu \mathrm{A})$ & 8.03145 & Std & $1.318531 \times 10^{-6}$ & & & & \\
\hline$R_{P}$ & 60.94008 & & & & & & \\
\hline$R_{S e}$ & 0.037954 & & & & & & \\
\hline$R_{S e}$ & 0.037954 & & & & & & \\
\hline
\end{tabular}

Table 6. Obtained optimal results and its comparison with literature available techniques proposed technique for SDM and DDM PV cell. (- indicates not provided by researchers).

\begin{tabular}{ccccc}
\hline Technique & \multicolumn{2}{c}{ SDM } & & DDM \\
\cline { 2 - 5 } & OF & AE & OF & AE \\
\hline Proposed PSO-ST & $7.730062 \times 10^{-4}$ & $2.14710 \times 10^{-4}$ & $7.183701 \times 10^{-4}$ & - \\
PSO & 9.5204 & - & $8.5353 \times 10^{-4}$ & - \\
CS [40] & $2.01185 \times 10^{-3}$ & - & $2.44398 \times 10^{-3}$ & - \\
TLBO [42] & $9.87332 \times 10^{-4}$ & - & & - \\
CLPSO [39] & $1.01347 \times 10^{-3}$ & - & $1.20232 \times 10^{-3}$ & - \\
GOTLBO [38] & & - & $9.89560 \times 10^{-4}$ & - \\
ABC [41] & $9.88148 \times 10^{-4}$ & - & $9.8248 \times 10^{-4}$ & - \\
HSDE-MFO [60] & & - & $9.8248 \times 10^{-4}$ & - \\
EADE [33] & & - & $9.8608 \times 10^{-4}$ & - \\
LFBSA [34] & $9.8602 \times 10^{-4}$ & - & $9.8248 \times 10^{-4}$ & - \\
ICSO [32] & & - & $9.84145 \times 10^{-4}$ & - \\
TLABC [43] & $9.86022 \times 10^{-4}$ & - & $9.834164 \times 10^{-4}$ & - \\
BFPA [35] & & - & $9.8607 \times 10^{-4}$ & - \\
ISCA [31] & - & - & $9.824849 \times 10^{-4}$ & - \\
GWO-CS [61] & $9.8334 \times 10^{-4}$ & - & $9.8295 \times 10^{-4}$ & - \\
MTLBO [62] & $9.860219 \times 10^{-4}$ & - & $9.82484 \times 10^{-4}$ & - \\
EBLSHADE [63] & & - & $7.4444 \times 10^{-4}$ & - \\
IMPA [64] & $9.86021 \times 10^{-4}$ & $8.73077 \times 10^{-4}$ & $7.424 \times 10^{-4}$ & - \\
CPSO [65] & $7.7301 \times 10^{-4}$ & - & $7.182745 \times 10^{-4}$ & - \\
TVACPSO [49] & $7.7301 \times 10^{-4}$ & - & - & - \\
ELPSO [66] & $7.7301 \times 10^{-4}$ & - & - \\
GCPSO [13] & $7.730063 \times 10^{-4}$ & & & - \\
\hline
\end{tabular}

\subsubsection{Single-Diode Module}

Five unknown parameters $\left(I_{\text {photon }}, I_{0}, R_{s e}, R_{P}, a\right)$ for the single diode model of the Photowatt-PWP201 PV Module obtained from the proposed PSO-ST are presented in Table 7. The best value of RMSE provided by these optimal parameters was $2.039992 \times 10^{-3}$ with standard deviation (SD) of $2.91529 \times 10^{-15}$ as presented in Table 6. Minimum, mean, and maximum values of RMSE, time, and required number of iterations are also presented in Table 7. The maximum and minimum values of RMSE were $2.039992 \times 10^{-3}$ and $2.039992 \times 10^{-3}$ respectively followed by required maximum and minimum iterations of 9931 and 761, respectively. Furthermore, 155 and 102 were the maximum and minimum time in seconds respectively, required for PSO-ST to converge. Experimental and computed values of the current are presented in Figure 9, which illustrates that the computed current obtained from an optimal set of parameters effectively approximate given experimental current for $26 \mathrm{I}-\mathrm{V}$ pairs. The plot of IAE for SDM is presented in Figure 10 and it can observe from this figure that the implemented technique provides minimum values of IAE for each 
I-V pair. Moreover, it can be observed that controlling tuning parameters of conventional PSO using the proposed approach provides such optimal parameters, which results in almost a similar trend of the I-V curve as obtained by experimental data sets. A comparison of obtained RMSE and AE from the proposed technique with the techniques available in the literature is also given for SDM. From where it can be observed that minimum RMSE and $\mathrm{AE}$ are obtained by the proposed technique in comparison with other techniques available in the literature. Moreover, from the comparison of obtained results with conventional PSO it is evident that the PSO-ST effectively balances the search mechanism of conventional PSO avoiding local minima stagnation and premature convergence problem.

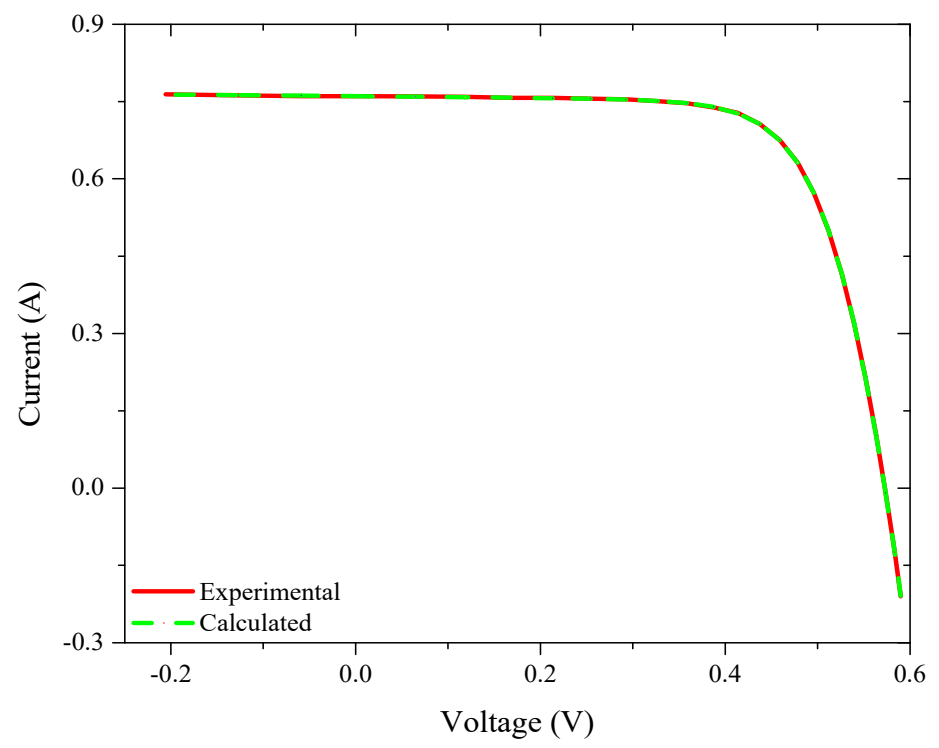

Figure 7. I-V curve for experimental and computed current values of DDM, solar cell.

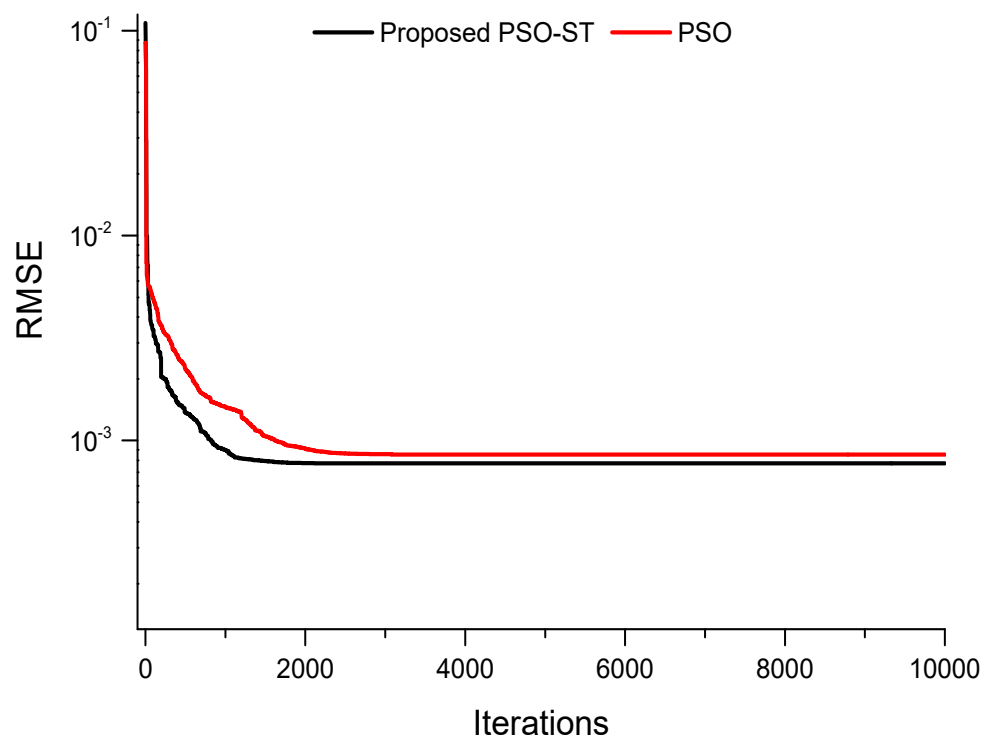

Figure 8. Convergence characteristics of DDM, solar cell.

\subsubsection{Double-Diode Module}

Similarly, seven unknown parameters $\left(I_{\text {photon }}, I_{01}, I_{02}, R_{s e}, R_{P}, a_{1}, a_{2}\right)$ for the double diode model of the Photowatt-PWP201 PV module obtained from the proposed PSO-ST are presented in Table 8. The best RMSE respective to these obtained parameters was $2.039992 \times 10^{-3}$ with STD of $2.05180 \times 10^{-15}$. The minimum value of RMSE indicates 
that proposed PSO-ST effectively explores search space while avoiding local minima stagnation. Minimum, mean, and maximum values of RMSE, time, and a required number of iterations are also presented in Table 8. The maximum and minimum values of RMSE were $2.039992 \times 10^{-3}$ and $2.039992 \times 10^{-3}$ respectively followed by required maximum and minimum iterations of 9999 and 1432, respectively. Furthermore, 281 and 125 were the maximum and minimum time in seconds required for PSO-ST to converge, respectively. Moreover, comparison of PSO-ST with state-of-the-art techniques available in the literature is also provided in Table 9, which demonstrates that the proposed technique provides the optimal value of RMSE. Furthermore, comparative evaluation of obtained results with conventional PSO strongly supports the presented modifications of inertia weight and acceleration coefficients. Experimental and computed values of current are presented in Figure 11, which illustrates that the computed current obtained from an optimal set of parameters effectively approximate the given experimental current for $26 \mathrm{I}-\mathrm{V}$ pairs. For case study 2, just like SDM a plot of IAE for DDM is also presented, from where it can be clearly seen that the proposed technique provides a minimum error. Furthermore, convergence characteristics of the proposed PSO-ST and conventional PSO in Figure 12 for the DDM module indicate that PSO-ST mitigates the premature convergence problem of PSO and provides fast convergence with optimal values of RMSE and PV parameters.

Table 7. Obtained statistical results for SDM PV module.

\begin{tabular}{lcclcccc}
\hline \multicolumn{2}{c}{$\begin{array}{c}\text { Obtained Optimal } \\
\text { Parameters }\end{array}$} & & OF & \multicolumn{2}{c}{ Iteration } & \multicolumn{2}{c}{ Time (s) } \\
\hline$I_{\text {photon }}(\mathrm{A})$ & 1.03237 & Min & $2.039992 \times 10^{-3}$ & Min & 761 & Min & 102 \\
$I_{0}(\mu \mathrm{A})$ & 2.49723 & Mean & $2.039992 \times 10^{-3}$ & Mean & 4532 & Mean & 104 \\
$a$ & 1.31666 & Max & $2.039992 \times 10^{-3}$ & Max & 9931 & Max & 155 \\
$R_{S e}$ & 1.24053 & Std & $2.91529 \times 10^{-15}$ & & & & \\
$R_{P}$ & 748.0465 & & & & & & \\
\hline
\end{tabular}

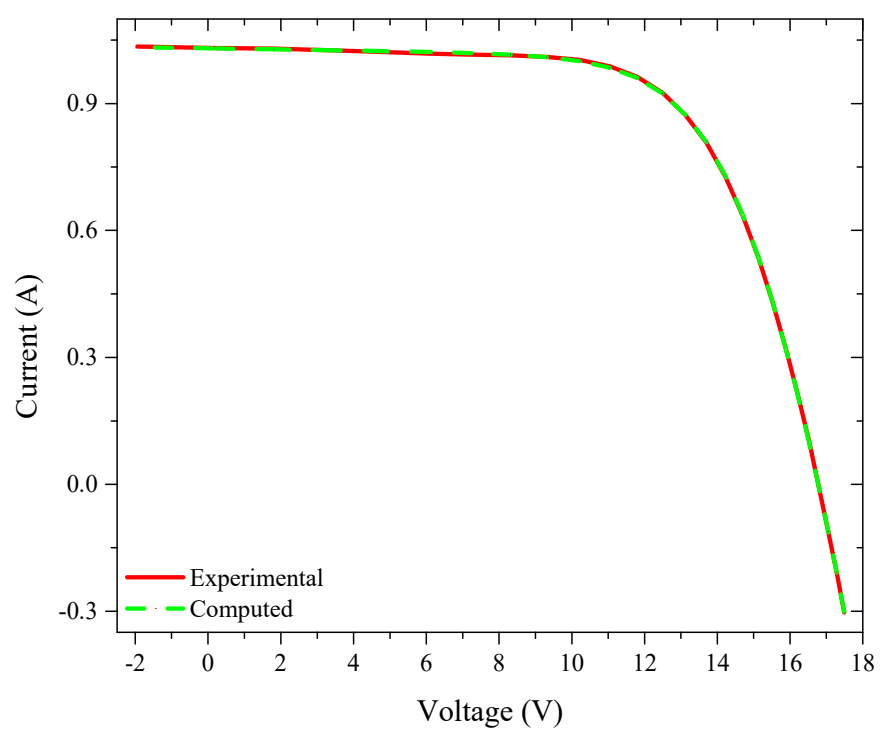

Figure 9. I-V curve of the SDM PV module for experimental and computed current values.

\subsection{Case 03: JKM330P-72, 310W Polycrystalline PV Module}

Five and seven unknown parameters for SDM and DDM modules were estimated utilizing the experimental I-V data obtained at $1000 \mathrm{~W} / \mathrm{m}^{2}$ irradiance and $47^{\circ} \mathrm{C}$ temperature. Furthermore, four other experimental curves with varying irradiance and temperature levels are also considered for parameter estimation using PSO-ST. Curve 1 is considered at $1000 \mathrm{~W} / \mathrm{m}^{2}$ and $47^{\circ} \mathrm{C}$ while curves $2,3,4$, and 5 were obtained at $800 \mathrm{~W} / \mathrm{m}^{2}$ and $44{ }^{\circ} \mathrm{C}, 600 \mathrm{~W} / \mathrm{m}^{2}$ at $42{ }^{\circ} \mathrm{C}, 400 \mathrm{~W} / \mathrm{m}^{2}$ at $36{ }^{\circ} \mathrm{C}$, and $200 \mathrm{~W} / \mathrm{m}^{2}$ at $27{ }^{\circ} \mathrm{C}$, respectively. 
JKM330P-72 is a PV module having 72 cells in series with characteristic point values of $V_{O C}=45.9 \mathrm{~V}, I_{S C}=8.96 \mathrm{~A}, I_{m p p}=8.38 \mathrm{~A}$, and $V_{m p p}=37.0 \mathrm{~V}$. The results from the proposed PSO-ST were obtained for 30 independent runs.

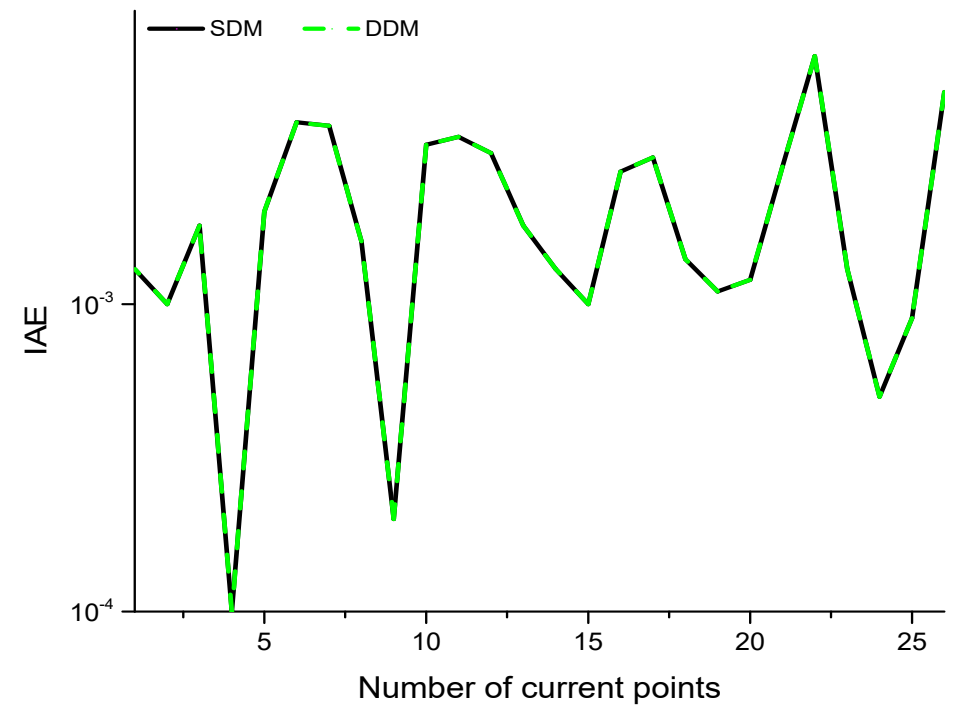

Figure 10. IAE for SDM and DDM, PV module.

Table 8. Obtained statistical results for the DDM PV module.

\begin{tabular}{lccccccc}
\hline \multicolumn{2}{c}{$\begin{array}{c}\text { Obtained Optimal } \\
\text { Parameters }\end{array}$} & & OF & Iteration & & Time (s) \\
\hline$I_{\text {photon }}(\mathrm{A})$ & 1.03237 & Min & $2.039992 \times 10^{-3}$ & Min & 1432 & Min & 125 \\
$I_{01}(\mu \mathrm{A})$ & 1.27653 & Mean & $2.039992 \times 10^{-3}$ & Mean & 8941 & Mean & 132 \\
$a_{1}$ & 1.31666 & Max & $2.039992 \times 10^{-3}$ & Max & 9999 & Max & 281 \\
$I_{02,}(\mu \mathrm{A})$ & $1.22078 \times 10^{-6}$ & Std & $2.05180 \times 10^{-15}$ & & & & \\
$a_{2}$ & 1.316656 & & & & & & \\
$R_{S e}$ & 1.240531 & & & & & & \\
$R_{P}$ & 748.0616 & & & & & & \\
\hline
\end{tabular}

Table 9. Obtained optimal results and its comparison with literature available techniques proposed technique for SDM and DDM PV module. (- indicates not provided by researchers).

\begin{tabular}{|c|c|c|c|c|}
\hline \multirow{2}{*}{ Techniques } & \multicolumn{2}{|c|}{ SDM } & \multicolumn{2}{|c|}{ DDM } \\
\hline & OF & $\mathrm{AE}$ & OF & $\mathrm{AE}$ \\
\hline Proposed PSO-ST & $2.039992 \times 10^{-3}$ & $5.5499 \times 10^{-3}$ & $2.039992 \times 10^{-3}$ & $5.5499 \times 10^{-3}$ \\
\hline PSO & $2.05455 \times 10^{-3}$ & - & $206341 \times 10^{-3}$ & - \\
\hline COA [17] & $2.9496 \times 10^{-3}$ & - & $2.4041 \times 10^{-3}$ & \\
\hline TLBO [42] & $2.42509 \times 10^{-3}$ & - & - & - \\
\hline BFPA [35] & $2.425075 \times 10^{-3}$ & - & - & - \\
\hline TLABC [43] & $2.42507 \times 10^{-3}$ & - & - & - \\
\hline GWO-CS [61] & $2.4251 \times 10^{-3}$ & - & - & - \\
\hline HSDE-MFO [60] & $2.4251 \times 10^{-3}$ & - & - & - \\
\hline EADE [33] & $2.4251 \times 10^{-3}$ & - & - & - \\
\hline EBLSHADE [63] & $2.4251 \times 10^{-3}$ & - & - & - \\
\hline LFBSA [34] & $2.4250 \times 10^{-3}$ & - & - & - \\
\hline ICSO [32] & $2.4250 \times 10^{-3}$ & - & - & - \\
\hline IMPA [64] & $2.42507 \times 10^{-3}$ & - & - & - \\
\hline MTLBO [62] & $2.42507 \times 10^{-3}$ & - & - & - \\
\hline GWO-CS [61] & $2.1903 \times 10^{-3}$ & - & $2.2138 \times 10^{-3}$ & - \\
\hline CPSO [65] & $2.0530 \times 10^{-3}$ & - & $2.0530 \times 10^{-3}$ & - \\
\hline TVACPSO [49] & $2.0530 \times 10^{-3}$ & - & $2.0530 \times 10^{-3}$ & - \\
\hline GCPSO [13] & $2.046535 \times 10^{-3}$ & $4.400032 \times 10^{-2}$ & $2.046535 \times 10^{-3}$ & $4.400032 \times 10^{-2}$ \\
\hline WDOWOAPSO [45] & $2.046535 \times 10^{-3}$ & $4.400032 \times 10^{-2}$ & $2.046535 \times 10^{-3}$ & $4.400033 \times 10^{-2}$ \\
\hline
\end{tabular}




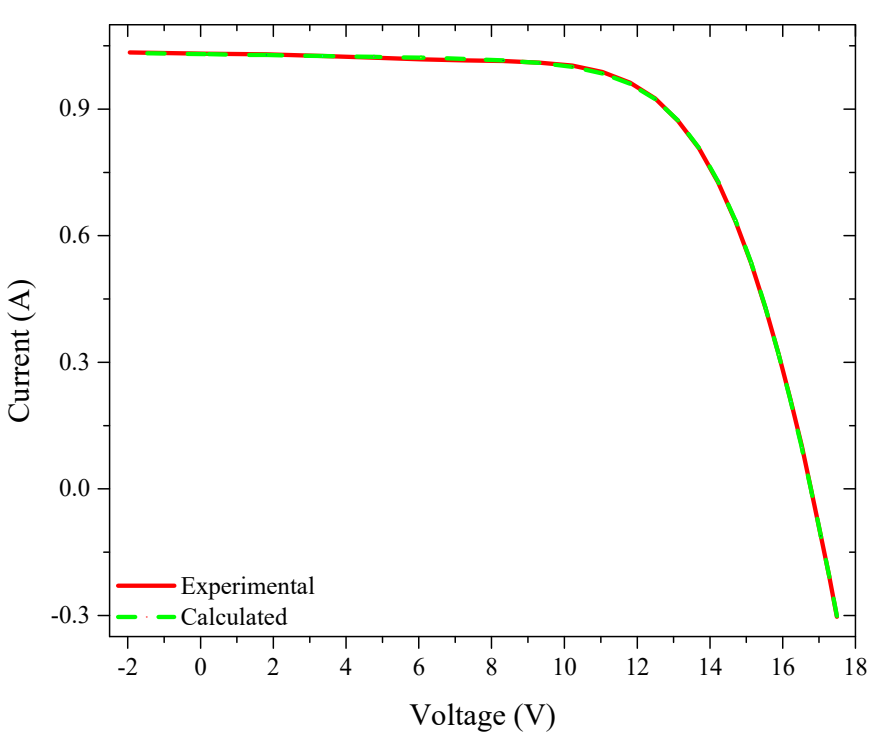

Figure 11. I-V curve of the DDM PV module for experimental and computed current values.

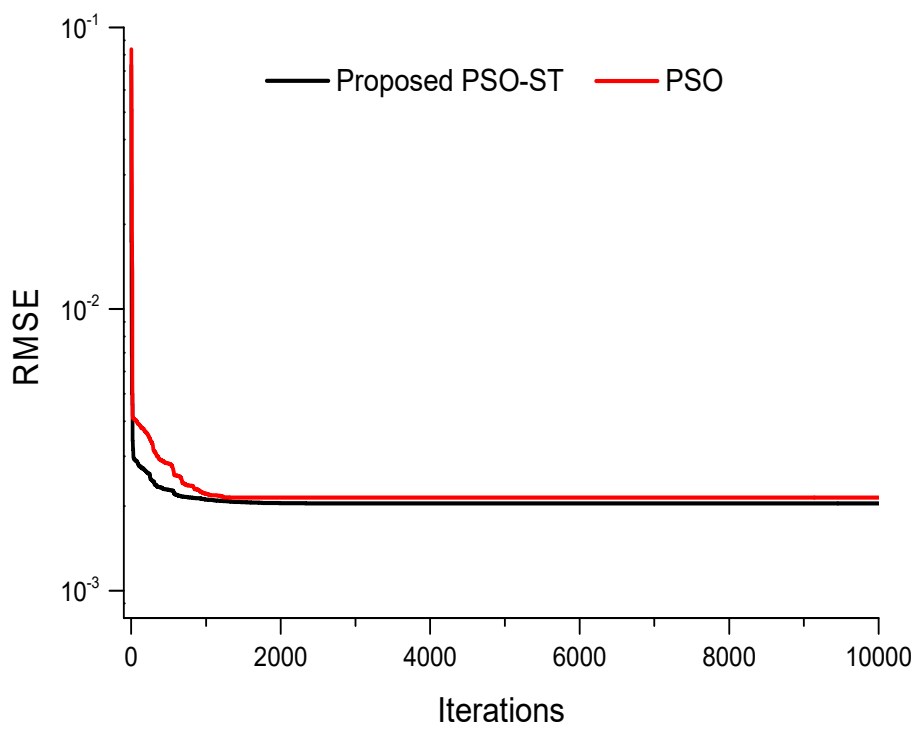

Figure 12. Convergence characteristics of DDM, PV module.

\subsubsection{Single-Diode Module}

Five unknown parameters $\left(I_{\text {photon }}, I_{0}, R_{s e}, R_{P}, a\right)$ for the single diode model of JKM330P-72, $310 \mathrm{~W}$ polycrystalline PV module obtained from the proposed PSO-ST are presented in Table 10 for curve 1. From Table 10, it can be observed that the best value of RMSE provided by these optimal parameters was 0.043114 with a standard deviation (SD) of $6.2983 \times 10^{-17}$. Minimum, mean, and maximum values of RMSE, time, and required number of iterations are also presented in Table 10. Maximum and minimum values of RMSE were 0.043114 and 0.043114 , respectively, followed by required maximum and minimum iterations of 9886 and 1951, respectively. Furthermore, 163 and 99 were the maximum and minimum time respectively in seconds required for PSO-ST to converge. Experimental and computed values of current for all respective curves are presented in Figure 13, which illustrates that the computed current obtained from an optimal set of parameters effectively approximates given experimental current for $26 \mathrm{I}-\mathrm{V}$ pairs. The plot of IAE for SDM (curv1) is presented in Figure 14, and it can observe from this figure that the implemented technique provides minimum values of IAE for each I-V pair. Moreover, it can be observed that controlling tuning parameters of conventional PSO using the 
proposed approach provides such optimal parameters, which results in almost a similar trend of I-V curve as obtained by experimental data sets. Table 11 presents a variation in RMSE, number of iterations, and time in sec for all respective curves of the SDM JKM330P-72 PV module.

Table 10. Obtained statistical results of SDM JKM330P-72 PV module for curve 1.

\begin{tabular}{|c|c|c|c|c|c|c|c|}
\hline \multicolumn{2}{|c|}{$\begin{array}{c}\text { Obtained Optimal } \\
\text { Parameters }\end{array}$} & \multicolumn{2}{|r|}{ OF } & \multicolumn{2}{|c|}{ Iteration } & \multicolumn{2}{|c|}{ Time (s) } \\
\hline$I_{\text {photon }}(\mathrm{A})$ & 9.882394 & Min & 0.043114 & Min & 1951 & Min & 99 \\
\hline$I_{0}(\mu \mathrm{A})$ & $2.63593 \times 10^{-1}$ & Mean & 0.043114 & Mean & 7288 & Mean & 109 \\
\hline$a$ & 1.292345 & Max & 0.043114 & Max & 9886 & Max & 163 \\
\hline$R_{S e}$ & 0.241931 & Std & $6.2983 \times 10^{-17}$ & & & & \\
\hline$R_{P}$ & 467.4168 & & & & & & \\
\hline
\end{tabular}

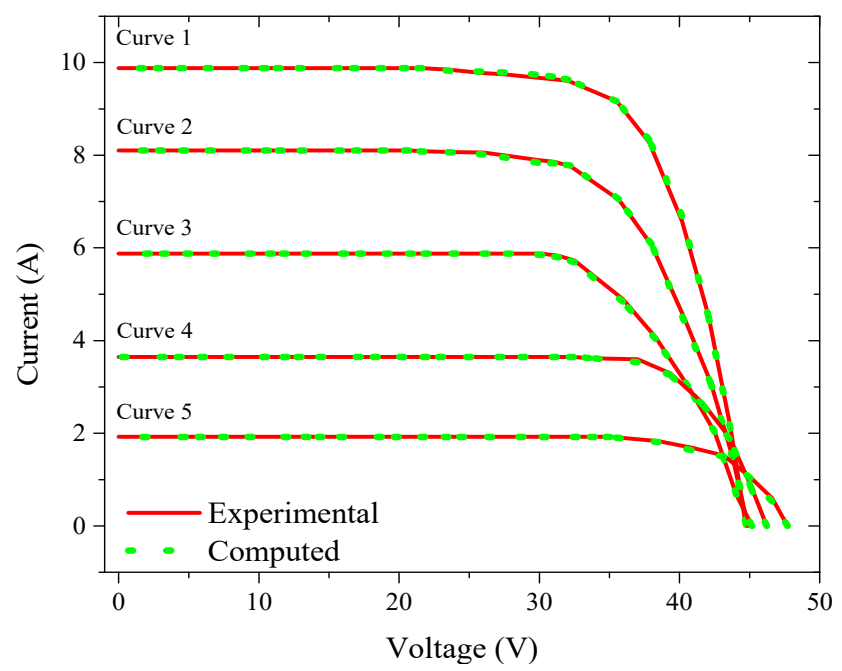

Figure 13. I-V curves of DDM, JKM330P-72 PV module for all respective curves.

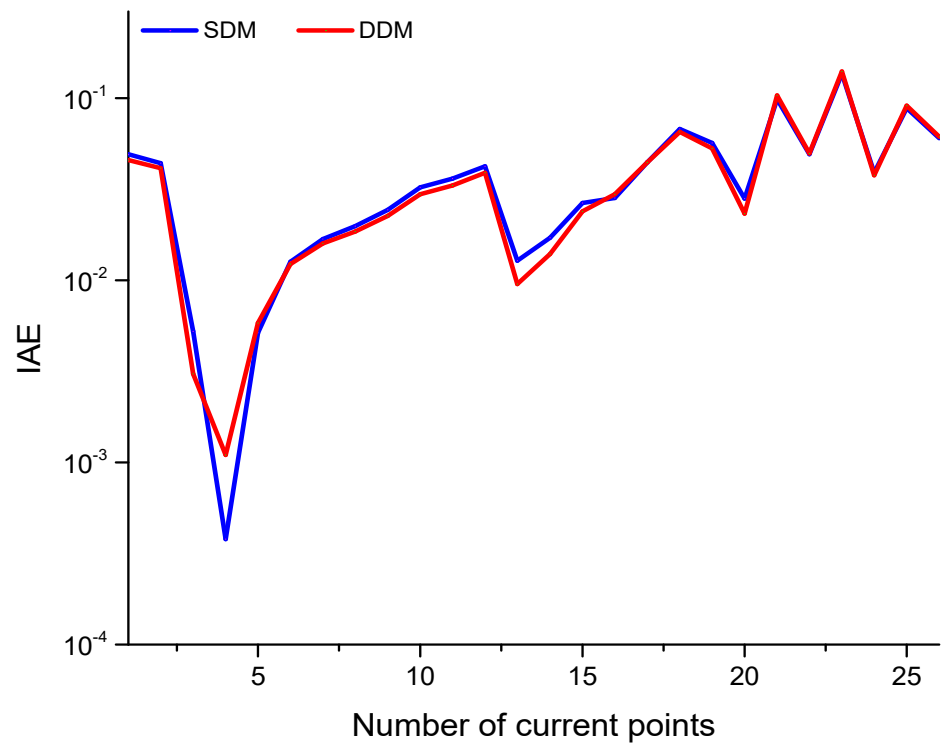

Figure 14. IAE for SDM and DDM, JKM330P-72 PV module for curve 1. 
Table 11. JKM330P-72 DDM PV module statistical results for all respective curves.

\begin{tabular}{cccccccccc}
\hline \multirow{2}{*}{$\begin{array}{c}\text { Experimental } \\
\text { Curves }\end{array}$} & \multicolumn{3}{c}{ RMSE } & \multicolumn{3}{c}{ Iteration } & \multicolumn{3}{c}{ Time (s) } \\
\cline { 2 - 10 } & Min & Mean & Max & Min & Mean & Max & Min & Mean & Max \\
\hline Curve-1 & 0.043114 & 0.043114 & 0.043114 & 1951 & 7288 & 9886 & 99 & 109 & 163 \\
Curve-2 & 0.054998 & 0.054998 & 0.054998 & 2582 & 8105 & 9999 & 155 & 166 & 184 \\
Curve-3 & 0.022270 & 0.022270 & 0.022270 & 2455 & 6283 & 8560 & 89 & 100 & 136 \\
Curve-4 & 0.035312 & 0.035312 & 0.035312 & 1043 & 5198 & 8890 & 93 & 95 & 109 \\
Curve-5 & 0.018006 & 0.018006 & 0.018006 & 961 & 5118 & 9999 & 86 & 91 & 97 \\
\hline
\end{tabular}

\subsubsection{Double-Diode Module}

Similarly, seven unknown parameters $\left(I_{\text {photon }}, I_{01}, I_{02}, R_{s e}, R_{P}, a_{1}, a_{2}\right)$ for the double diode model of the polycrystalline PV module obtained from the proposed PSO-ST are presented in Table 12 for curve 1. The best RMSE respective to these obtained parameters was 0.042419 with STD of $9.12281 \times 10^{-5}$. Minimum, mean, and maximum values of RMSE, time, and required number of iterations are also presented in Table 12. Maximum and minimum values of RMSE were 0.043270 and 0.042419 respectively, followed by required maximum and minimum iterations of 10000 and 2188 respectively. Furthermore, 189 and 123 were the maximum and minimum time respectively in seconds required for PSO-ST to converge. The individual absolute error (IAE) for the obtained current respective to each pair of I-V curve data with absolute error (AE) of all I-V data sets for curve 1 is also given and it can be observe from this figure that the implemented technique provides minimum values of IAE for each I-V pair. Experimental and computed values of current for all respective curves are presented in Figure 15, which illustrates that the computed current obtained from the optimal set of parameters affectively approximate the given experimental current for $26 \mathrm{I}-\mathrm{V}$ pairs. Table 13 presents a variation in RMSE, number of iterations, and time in seconds for all respective curves. Moreover, it can be observed that controlling tuning parameters of conventional PSO using the proposed approach provides such optimal parameters, which results in almost a similar trend of the I-V curve as obtained by experimental data sets. Convergence curve for DDM module is presented in Figure 16.

Table 12. Obtained statistical results for DDM JKM330P-72 PV module for curve 1.

\begin{tabular}{|c|c|c|c|c|c|c|c|}
\hline \multicolumn{2}{|c|}{$\begin{array}{l}\text { Obtained Optimal } \\
\text { Parameters }\end{array}$} & \multicolumn{2}{|r|}{ OF } & \multicolumn{2}{|c|}{ Iteration } & \multicolumn{2}{|c|}{ Time (s) } \\
\hline$I_{\text {photon }}(\mathrm{A})$ & 9.877970 & Min & 0.042419 & Min & 2188 & Min & 123 \\
\hline$I_{01}(\mu \mathrm{A})$ & 9.998772 & Mean & 0.042398 & Mean & 7321 & Mean & 141 \\
\hline$a_{1}$ & 2.039768 & Max & 0.043207 & Max & 10000 & $\operatorname{Max}$ & 189 \\
\hline$I_{02}(\mu \mathrm{A})$ & $1.17142 \times 10^{-1}$ & Std & $9.12281 \times 10^{-5}$ & & & & \\
\hline$a_{2}$ & 1.239257 & & & & & & \\
\hline$R_{S e}$ & 0.247091 & & & & & & \\
\hline$R_{P}$ & 587.5669 & & & & & & \\
\hline
\end{tabular}

Table 13. JKM330P-72 DDM PV module statistical results for all respective curves.

\begin{tabular}{cccccccccc}
\hline \multirow{2}{*}{$\begin{array}{c}\text { Experimental } \\
\text { Curves }\end{array}$} & \multicolumn{3}{c}{ RMSE } & \multicolumn{3}{c}{ Iteration } & \multicolumn{3}{c}{ Time (s) } \\
\cline { 2 - 10 } & Min & Mean & Max & Min & Mean & Max & Min & Mean & Max \\
\hline Curve-1 & 0.042419 & 0.042398 & 0.043207 & 2188 & 7321 & 10000 & 123 & 141 & 189 \\
Curve-2 & 0.043299 & 0.043299 & 0.043299 & 4998 & 8365 & 10000 & 137 & 168 & 196 \\
Curve-3 & 0.022270 & 0.022270 & 0.022270 & 3280 & 9103 & 10000 & 100 & 110 & 141 \\
Curve-4 & 0.035292 & 0.035292 & 0.035292 & 1674 & 7014 & 10000 & 98 & 129 & 172 \\
Curve-5 & 0.018041 & 0.018041 & 0.018041 & 2114 & 5983 & 10000 & 100 & 126 & 143 \\
\hline
\end{tabular}




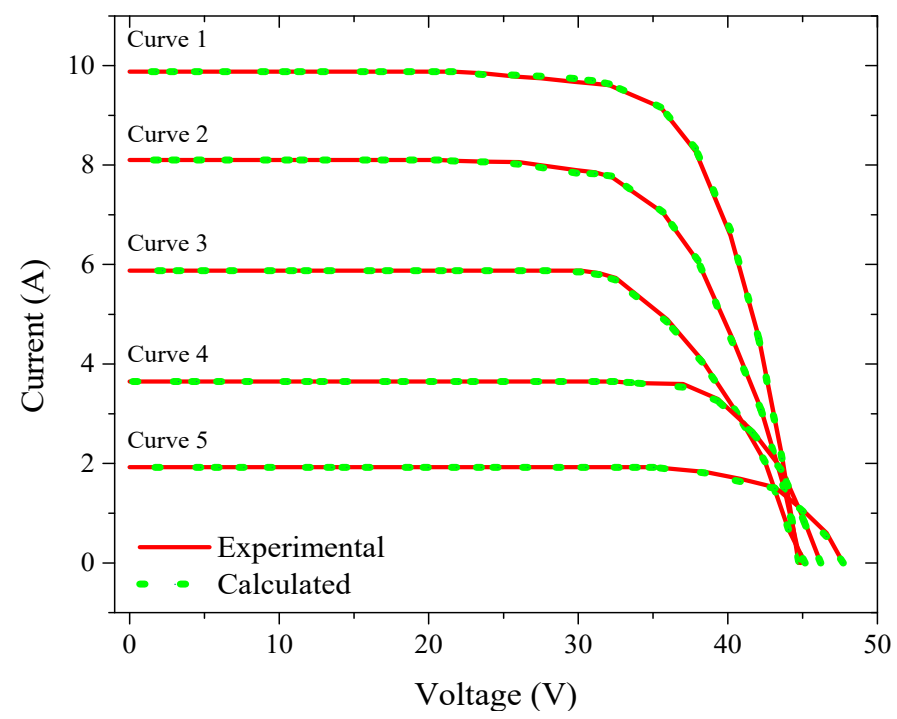

Figure 15. I-V curves of DDM, JKM330P-72 PV module for all respective curves.

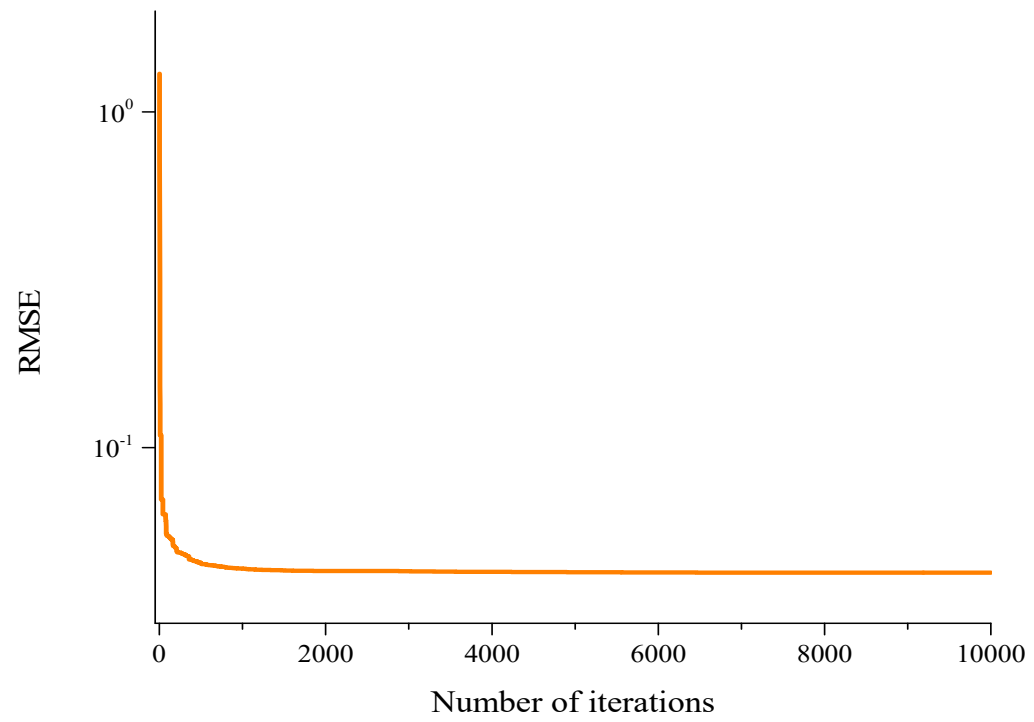

Figure 16. Convergence characteristics of DDM, JKM330P-72 PV module for curve 1.

\section{Conclusions}

This paper presents an improved variant of PSO based on chaos theory and trigonometric functions named as PSO-ST to solve the premature convergence problem and local optima stagnation of conventional PSO for quick, effective, and optimal extraction of PV parameters. The improved PSO (PSO-ST) provides appropriate values of controlling parameters utilizing sine chaotic and tangent chaotic strategies to control inertia weight and acceleration coefficients, respectively. The proposed method has been validated on single and double diode models for three different case studies. Results obtained from the proposed approach have been compared with various techniques available in the literature. For the RTC France solar cell, the proposed technique provides better results for the double diode model at the cost of a greater computational burden than the single diode model. In the case of the Photowatt-PWP201 PV module, single and double diode models show the same results in terms of RMSE, but DDM is computationally cumbersome because of the number of unknown parameters involved. Finally, the proposed framework also offers better efficiency for practical JKM330P-72, $310 \mathrm{~W}$ polycrystalline single and double diode PV modules under different environmental conditions. Results for case study-3 illustrate that the double diode module has as better performance for both high and low 
irradiance levels in terms of RMSE. Furthermore, convergence comparison of proposed and conventional PSO reveals that PSO-ST provides better and fast convergence characteristics. Moreover, a comparison of obtained results in terms of RMSE with techniques available in the literature shows that the proposed variant of PSO (PSO-ST) is an efficient, effective, and accurate tool for estimating PV parameters.

Author Contributions: Methodology and writeup: A.T.K.; supervision: M.F.N.; Conceptualization and validation: A.A.; data curation: I.A.K.; Review: H.I.A.; proofread and edit: I.A.S.; data curation: B.H. All authors have read and agreed to the published version of the manuscript.

Funding: No external funding is provided for this research work.

Acknowledgments: The authors would like to acknowledge the support from Taif University Researchers Supporting Project Number (TURSP-2020/264), Taif University, Taif, Saudi Arabia.

Conflicts of Interest: Authors declare no conflict of interests.

$\begin{array}{ll}\text { Nomenclature } \\ e & \text { charge on electron. } \\ R_{p} & \text { parallel resistance } \\ R_{s e} & \text { series resistance } \\ I_{0} & \text { diodes saturation current } \\ a & \text { diodes ideality factor. } \\ I_{\text {photon }} & \text { photon current } \\ c_{1} & \text { personal acceleration coefficient } \\ c_{2} & \text { social acceleration coefficient } \\ I_{z} & \text { experimental current } \\ I_{\left(V_{z}, t\right)} & \text { measured current } \\ \mathcal{G}_{b e s t} & \text { global best } \\ \mathcal{P}_{b e s t} & \text { personal best } \\ w & \text { inertia weight } \\ k & \text { Boltzmann constant } \\ \text { Te } & \text { temperature in Kelvin } \\ N & \text { number of I-V pairs }\end{array}$

\section{References}

1. Ahmed, A.; Faisal, M.; Ali, I.; Bo, R.; Khan, I.A. Probabilistic generation model for optimal allocation of wind DG in distribution systems with time varying load models. Sustain. Energy Grids Netw. 2020, 22, 100358. [CrossRef]

2. Ahmed, A.; Nadeem, M.F.; Sajjad, I.A.; Bo, R.; Khan, I.A. Optimal Allocation of Wind DG with Time Varying Voltage Dependent Loads Using Bio-Inspired: Salp Swarm Algorithm. In Proceedings of the 2020 3rd International Conference on Computing, Mathematics and Engineering Technologies iCoMET, Sukkur, Pakistan, 29-30 January 2020; pp. 1-7.

3. Ahmed, A.; Faisal, M.; Khan, N.; Khan, I.; Member, S.; Alquhayz, H.; Khan, M.A.; Kiani, A.T. A Novel Framework to Determine the Impact of Time Varying Load Models on Wind DG Planning. IEEE Access 2021, 9, 1-16. [CrossRef]

4. Moayedi, H.; Mosavi, A. An Innovative Metaheuristic Strategy for Solar Energy. Energies 2021, 14, 1196. [CrossRef]

5. Guezgouz, M.; Jurasz, J.; Mikulik, J.; Paweł, B.D. Complementarity and ' Resource Droughts ' of Solar and Wind Energy in Poland: An ERA5-Based Analysis. Energies 2021, 14, 1118. [CrossRef]

6. Carreño-Ortega, A.; Galdeano-Gómez, E.; Pérez-Mesa, J.C.; Galera-Quiles, M.D.C. Policy and environmental implications of photovoltaic systems in farming in southeast Spain: Can greenhouses reduce the greenhouse effect? Energies 2017, 10, 761. [CrossRef]

7. Ul-Haq, A.; Cecati, C.; Al-Ammar, E.A. Modeling of a photovoltaic-powered electric vehicle charging station with vehicle-to-grid implementation. Energies 2017, 10, 4. [CrossRef]

8. Sutopo, W.; Mardikaningsih, I.S.; Zakaria, R.; Ali, A. A model to improve the implementation standards of street lighting based on solar energy: A case study. Energies 2020, 13, 630. [CrossRef]

9. Farh, H.M.H.; Othman, M.F.; Eltamaly, A.M.; Al-Saud, M.S. Maximum power extraction from a partially shaded PV system using an interleaved boost converter. Energies 2018, 11, 2543. [CrossRef]

10. Das, B.K.; Hasan, M. Optimal sizing of a stand-alone hybrid system for electric and thermal loads using excess energy and waste heat. Energy 2021, 214, 119036. [CrossRef]

11. De Sá Campos, M.H.S.; de Tiba, C. npTrack: A n-Position Single Axis Solar Tracker Model for Optimized Energy Collection. Energies 2021, 14, 925. [CrossRef]

12. Xue, B.; Li, F; Song, M.; Shang, X.; Cui, D.; Chu, J; Dai, S. Crack Extraction for Polycrystalline Solar Panels. Energies 2021, 14, 374. [CrossRef] 
13. Nunes, H.G.G.; Pombo, J.A.N.; Mariano, S.J.P.S.; Calado, M.R.A.; Felippe de Souza, J.A.M. A new high performance method for determining the parameters of PV cells and modules based on guaranteed convergence particle swarm optimization. Appl. Energy 2018, 211, 774-791. [CrossRef]

14. Humada, A.M.; Darweesh, S.Y.; Mohammed, K.G.; Kamil, M.; Mohammed, S.F.; Kasim, N.K.; Tahseen, T.A.; Awad, O.I.; Mekhilef, S. Modeling of PV system and parameter extraction based on experimental data: Review and investigation. Sol. Energy 2020, 199, 742-760. [CrossRef]

15. Soon, J.J.; Low, K.S. Optimizing Photovoltaic Model for Different Cell Technologies Using a Generalized Multidimension Diode Model. IEEE Trans. Ind. Electron. 2015, 62, 6371-6380. [CrossRef]

16. Rasheed, M.; Shihab, S.; Rashid, T.; Maalej, O. Determining the Voltage and Power of a Single Diode PV Cell in Matlab by Iteration. J. Al Qadisiyah Comput. Sci. Math. 2021, 13, 70-78.

17. DIab, A.A.Z.; Sultan, H.M.; Do, T.D.; Kamel, O.M.; Mossa, M.A. Coyote Optimization Algorithm for Parameters Estimation of Various Models of Solar Cells and PV Modules. IEEE Access 2020, 8, 111102-111140. [CrossRef]

18. Maouhoub, N. Photovoltaic module parameter estimation using an analytical approach and least squares method. J. Comput. Electron. 2018, 17, 784-790. [CrossRef]

19. Jordehi, A.R. Parameter estimation of solar photovoltaic (PV) cells: A review. Renew. Sustain. Energy Rev. 2016, 61, 354-371. [CrossRef]

20. Et-torabi, K.; Nassar-eddine, I.; Obbadi, A.; Errami, Y.; Rmaily, R.; Sahnoun, S.; El Fajri, A.; Agunaou, M. Parameters estimation of the single and double diode photovoltaic models using a Gauss-Seidel algorithm and analytical method: A comparative study. Energy Convers. Manag. 2017, 148, 1041-1054. [CrossRef]

21. Reis, L.R.D.; Camacho, J.R.; Novacki, D.F. The newton raphson method in the extraction of parameters of PV modules. Renew. Energy Power Qual. J. 2017, 1, 634-639. [CrossRef]

22. Nassar-Eddine, I.; Obbadi, A.; Errami, Y.; El Fajri, A.; Agunaou, M. Parameter estimation of photovoltaic modules using iterative method and the Lambert W function: A comparative study. Energy Convers. Manag. 2016, 119, 37-48. [CrossRef]

23. Ćalasan, M.; Abdel Aleem, S.H.E.; Zobaa, A.F. On the root mean square error (RMSE) calculation for parameter estimation of photovoltaic models: A novel exact analytical solution based on Lambert W function. Energy Convers. Manag. 2020, 210, 112716. [CrossRef]

24. Cubas, J.; Pindado, S.; De Manuel, C. Explicit expressions for solar panel equivalent circuit parameters based on analytical formulation and the lambert W-function. Energies 2014, 7, 4098-4115. [CrossRef]

25. Rajasekar, N.; Krishna Kumar, N.; Venugopalan, R. Bacterial Foraging Algorithm based solar PV parameter estimation. Sol. Energy 2013, 97, 255-265. [CrossRef]

26. Alam, D.F.; Yousri, D.A.; Eteiba, M.B. Flower Pollination Algorithm based solar PV parameter estimation. Energy Convers. Manag. 2015, 101, 410-422. [CrossRef]

27. Kang, T.; Yao, J.; Jin, M.; Yang, S.; Duong, T. A novel improved cuckoo search algorithm for parameter estimation of photovoltaic (PV) models. Energies 2018, 11, 1060. [CrossRef]

28. Ishaque, K.; Salam, Z. An improved modeling method to determine the model parameters of photovoltaic (PV) modules using differential evolution (DE). Sol. Energy 2011, 85, 2349-2359. [CrossRef]

29. Ishaque, K.; Salam, Z.; Mekhilef, S.; Shamsudin, A. Parameter extraction of solar photovoltaic modules using penalty-based differential evolution. Appl. Energy 2012, 99, 297-308. [CrossRef]

30. Fathy, A.; Elaziz, M.A.; Sayed, E.T.; Olabi, A.G.; Rezk, H. Optimal parameter identification of triple-junction photovoltaic panel based on enhanced moth search algorithm. Energy 2019, 188, 116025. [CrossRef]

31. Chen, H.; Jiao, S.; Heidari, A.A.; Wang, M.; Chen, X.; Zhao, X. An opposition-based sine cosine approach with local search for parameter estimation of photovoltaic models. Energy Convers. Manag. 2019, 195, 927-942. [CrossRef]

32. Gude, S.; Jana, K.C. Parameter extraction of photovoltaic cell using an improved cuckoo search optimization. Sol. Energy 2020, 204, 280-293. [CrossRef]

33. Gong, W.; Cai, Z. Parameter extraction of solar cell models using repaired adaptive differential evolution. Sol. Energy 2013, 94, 209-220. [CrossRef]

34. Zhang, Y.; Jin, Z.; Zhao, X.; Yang, Q. Backtracking search algorithm with Lévy flight for estimating parameters of photovoltaic models. Energy Convers. Manag. 2020, 208, 112615. [CrossRef]

35. Xu, S.; Wang, Y. Parameter estimation of photovoltaic modules using a hybrid flower pollination algorithm. Energy Convers. Manag. 2017, 144, 53-68. [CrossRef]

36. Subudhi, B.; Pradhan, R. Bacterial Foraging Optimization approach to parameter extraction of a photovoltaic module. IEEE Trans. Sustain. Energy 2018, 9, 381-389. [CrossRef]

37. Ramadan, A.; Kamel, S.; Korashy, A.; Yu, J. Photovoltaic Cells Parameter Estimation Using an Enhanced Teaching-Learning-Based Optimization Algorithm. Iran. J. Sci. Technol. Trans. Electr. Eng. 2020, 44, 767-779. [CrossRef]

38. Chen, X.; Yu, K.; Du, W.; Zhao, W.; Liu, G. Parameters identification of solar cell models using generalized oppositional teaching learning based optimization. Energy 2016, 99, 170-180. [CrossRef]

39. Liang, J.J.; Qin, A.K.; Member, S.; Suganthan, P.N.; Member, S.; Baskar, S. Comprehensive learning PSO for global optimization of multimodal functions. IEEE Trans. Evol. Comput. 2006, 10, 281-295. [CrossRef]

40. Ma, J.; Ting, T.O.; Man, K.L.; Zhang, N.; Guan, S.U.; Wong, P.W.H. Parameter estimation of photovoltaic models via cuckoo search J. Appl. Math. 2013, 2013, 10-12. [CrossRef] 
41. Oliva, D.; Cuevas, E.; Pajares, G. Parameter identification of solar cells using artificial bee colony optimization. Energy 2014, 72, 93-102. [CrossRef]

42. Rao, R.V.; Savsani, V.J.; Vakharia, D.P. Teaching-Learning-Based Optimization: An optimization method for continuous non-linear large scale problems. Inf. Sci. 2012, 183, 1-15. [CrossRef]

43. Chen, X.; Xu, B.; Mei, C.; Ding, Y.; Li, K. Teaching-learning-based artificial bee colony for solar photovoltaic parameter estimation. Appl. Energy 2018, 212, 1578-1588. [CrossRef]

44. Ahmed, A.; Nadeem, M.F.; Kiani, A.T.; Khan, I. An Overview on Optimal Planning of Distributed Generation in Distribution system and Key Issues. In Proceedings of the 2021 IEEE Texas Power and Energy Conference (TPEC), IEEE, College Station, TX, USA, 2-5 February 2021; pp. 1-6.

45. Nunes, H.G.G.; Pombo, J.A.N.; Bento, P.M.R.; Mariano, S.J.P.S.; Calado, M.R.A. Collaborative swarm intelligence to estimate PV parameters. Energy Convers. Manag. 2019, 185, 866-890. [CrossRef]

46. Mughal, M.A.; Ma, Q.; Xiao, C. Photovoltaic cell parameter estimation using hybrid particle swarm optimization and simulated annealing. Energies 2017, 10, 1213. [CrossRef]

47. Farhana, N.; Hamid, A.; Rahim, A.; Selvaraj, J. Solar cell parameters identification using hybrid Nelder-Mead and modified particle Solar cell parameters identification using hybrid Nelder-Mead and modified particle swarm optimization. J. Renew. Sustain. Energy 2016, 8, 015502. [CrossRef]

48. Sharma, A.; Sharma, A.; Averbukh, M.; Jately, V. An Effective Method for Parameter Estimation of a Solar Cell. Electronics 2021, 10, 312. [CrossRef]

49. Jordehi, A.R. Time varying acceleration coefficients particle swarm optimisation (TVACPSO): A new optimisation algorithm for estimating parameters of PV cells and modules. Energy Convers. Manag. 2016, 129, 262-274. [CrossRef]

50. Kiani, A.T.; Faisal Nadeem, M.; Ahmed, A.; Sajjad, I.A.; Raza, A.; Khan, I.A. Chaotic Inertia Weight Particle Swarm Optimization (CIWPSO): An Efficient Technique for Solar Cell Parameter Estimation. In Proceedings of the 2020 3rd International Conference on Computing, Mathematics and Engineering Technologies (iCoMET), Sukkur, Pakistan, 29-30 January 2020. [CrossRef]

51. Kiani, A.T.; Nadeem, M.F.; Ahmed, A.; Sajjad, I.A.; Haris, M.S.; Martirano, L. Optimal Parameter Estimation of Solar Cell using Simulated Annealing Inertia Weight Particle Swarm Optimization (SAIW-PSO). In Proceedings of the 2020 IEEE International Conference on Environment and Electrical Engineering and 2020 IEEE Industrial and Commercial Power Systems Europe (EEEIC / I\&CPS Europe), Madrid, Spain, 9-12 June 2020; pp. 1-6. [CrossRef]

52. Kiani, A.T.; Nadeem, M.F.; Ahmed, A.; Khan, I.; Elavarasan, R.M.; Das, N. Exponential Function-Based Dynamic Inertia Weight Particle Swarm Optimization. Energies 2020, 13, 37. [CrossRef]

53. Shi, Y.; Eberhart, R.C. Empirical study of particle swarm optimization. Proc. 1999 Congr. Evol. Comput. CEC 1999 1999, 3, 1945-1950. [CrossRef]

54. Yusup, N.; Mohd, A.; Zaiton, S.; Hashim, M. Expert Systems with Applications Evolutionary techniques in optimizing machining parameters: Review and recent applications (2007-2011). Expert Syst. Appl. 2012, 39, 9909-9927. [CrossRef]

55. Sibalija, T.; Petronic, S.; Milovanovic, D. Experimental Optimization of Nimonic 263 Laser Cutting Using a Particle Swarm Approach. Metals 2019, 9, 1147. [CrossRef]

56. Du, Y.; Xu, F. Numerical Function Optimization. Symmetry 2020, 12, 922. [CrossRef]

57. Imran, M.; Hashim, R.; Khalid, N.E.A. An overview of particle swarm optimization variants. Procedia Eng. 2013, 53, 491-496. [CrossRef]

58. Chen, G. Chaos Theory and Applications: A New Trend. Chaos Theory Appl. 2021, 3, 1-2.

59. Ma, Z.; Yuan, X.; Han, S.; Sun, D.; Ma, Y. Improved chaotic particle swarm optimization algorithm with more symmetric distribution for numerical function optimization. Symmetry 2019, 11, 876. [CrossRef]

60. Wu, Y.; Chen, R.; Li, C.; Zhang, L.; Cui, Z. Hybrid Symbiotic Differential Evolution Moth-Flame Optimization Algorithm for Estimating Parameters of Photovoltaic Models. IEEE Access 2020, 8, 156328-156346. [CrossRef]

61. Long, W.; Cai, S.; Jiao, J.; Xu, M.; Wu, T. A new hybrid algorithm based on grey wolf optimizer and cuckoo search for parameter extraction of solar photovoltaic models. Energy Convers. Manag. 2020, 203, 112243. [CrossRef]

62. Abdel-Basset, M.; Mohamed, R.; Chakrabortty, R.K.; Sallam, K.; Ryan, M.J. An efficient teaching-learning-based optimization algorithm for parameters identification of photovoltaic models: Analysis and validations. Energy Convers. Manag. 2021, 227, 113614. [CrossRef]

63. Song, Y.; Wu, D.; Wagdy Mohamed, A.; Zhou, X.; Zhang, B.; Deng, W. Enhanced Success History Adaptive DE for Parameter Optimization of Photovoltaic Models. Complexity 2021, 2021, 1-22. [CrossRef]

64. Abdel-Basset, M.; El-Shahat, D.; Chakrabortty, R.K.; Ryan, M. Parameter estimation of photovoltaic models using an improved marine predators algorithm. Energy Convers. Manag. 2021, 227, 113491. [CrossRef]

65. Guo, L.; Meng, Z.; Sun, Y.; Wang, L. Parameter identification and sensitivity analysis of solar cell models with cat swarm optimization algorithm. Energy Convers. Manag. 2016, 108, 520-528. [CrossRef]

66. Rezaee Jordehi, A. Enhanced leader particle swarm optimisation (ELPSO): An efficient algorithm for parameter estimation of photovoltaic (PV) cells and modules. Sol. Energy 2018, 159, 78-87. [CrossRef] 